\title{
HUMAN MEIOSIS V. SUBSTAGES OF PACHYTENE IN HUMAN SPERMATOGENESIS
}

\author{
by \\ PREBEN BACH HOLM \\ and \\ SØREN WILKEN RASMUSSEN \\ Department of Physiology, Carlsberg Laboratory, \\ Gamle Carlsberg Vej 10, DK-2500 Copenhagen, Valby
}

Keywords: Synaptonemal complex, centromere, nucleolus, XY bivalent, recombination nodule

The pachytene stage of human spermatogenesis has been investigated by serial sectioning of spermatocytes and three dimensional reconstruction of nuclei from electron micrographs. The analysis of 73 completely reconstructed normal nuclei from late zygotene to early diplotene revealed a continuous sequence of changes in the fine structure and morphology. The developmental sequence permits the recognition of 7 substages on the basis of morphological changes of autosomal chromatin, centromeric chromatin, the XY bivalent, the secondary constriction on bivalents 1,9 and 16 , the nucleolus and the centrioles. Of particular interest is the observation that the disappearance of the synaptonemal complex segment between the $X$ and $Y$ chromosomes at mid pachytene is only temporary, a distinct complex segment being present in nearly all analysed $X Y$ bivalents by the end of pachytene. The number of recombination nodules and recombination bars in nuclei of the different substages is recorded. The total number of nodules decreases from 75 at the beginning of pachytene to 1 or none at the end of this stage. The bars appear at early pachytene, reach a number of 35 at mid pachytene and disappear following the nodules towards the end of pachytene. The morphology of pachytene nuclei at various stages of degeneration as well as the structural characteristics of two tetraploid spermatocytes are described.

\section{INTRODUCTION}

A number of recent investigations have strongly supported the contention (3) that meiotic recombination is mediated by electron dense nodes - recombination nodules - associated with the central region of the synaptonemal complex $(4,5,9,12)$. By determining the number and distribution of recombination nodules during zygotene and pachytene it has been shown that the final pattern which corresponds to the distribution of crossovers and chiasmata is established through a series of numerical and distributional changes converting an initially random 
Table I.

The number, origin and stage of the 73 completely reconstructed pachytene nuclei. For further details on cases 1 - 5 and the translocation heterozygote see $(8,13)$

\begin{tabular}{|c|c|c|c|c|c|c|}
\hline $\begin{array}{l}\text { Pachytene } \\
\text { stage }\end{array}$ & Case 1 & Case 2 & Case 3 & Case 4 & Case 5 & Transl. \\
\hline 1 & - & - & $54-61$ & 43,44 & $62-65$ & $\begin{array}{l}39-41 \\
47-50\end{array}$ \\
\hline 2 & - & - & $\begin{array}{c}25,27,28 \\
89-94\end{array}$ & $58-60$ & - & - \\
\hline 3 & - & - & $78-80$ & $70-73$ & $81-88$ & - \\
\hline 4 & - & $7-9,11,12$ & - & - & - & - \\
\hline 5 & 2,4 & - & $13-15$ & $19,34-36$ & - & - \\
\hline 6 & 1,3 & - & - & - & 21,22 & - \\
\hline 7 & - & - & $\begin{array}{l}23,26 \\
42-46\end{array}$ & - & - & - \\
\hline
\end{tabular}

distribution of nodules along and among the bivalents into a nonrandom one $(4,9,12,13)$. This reallocation which ensures a minimum of one nodule per bivalent and a distribution along the bivalent arms characteristic for a given species is generally accompanied by morphological changes of nodule ultrastructure and eventually results in the formation of the chiasma (9), the structural consequence of crossing over.

The analysis of reallocation is dependent upon a reproducible subdivision of the zygotene and pachytene stages in order to achieve the necessary resolution of the temporal changes in nodule distribution. While the pachytene stage, in the organisms where these problems have been investigated during the entire prophase, can be divided into well-defined substages on the basis of nuclear and/or cellular morphology $(4,9,12)$ the situation in the human male is more complex. The pachytene stage of human spermatogenesis has been estimated to last 16 days (6) during which the nuclei undergo substantial changes in fine structure. This, in combination with the lack of information on the morphology of nuclei at the pachytene-diplotene transition, have led to conflicting proposals for the temporal sequence of events, in particular, concerning the pattern of chromatin condensation during pachytene.

In a recent investigation, SOLARI (16) reported that bar-like structures were present during the entire pachytene stage in numbers roughly corresponding to the number of chiasmata and distributed similarly. These observations are at vari- ance with the much lower number of bars reported by BERTHELSEN et al. (1) and neither of the investigations explored the relationship between recombination nodules, bars and chiasmata. With the exception of the zygotene stage and the very first period of pachytene (13) the progressive changes in structure, number and distribution of the recombination nodules during human spermatogenesis have thus not been satisfactorily mapped.

The present analysis of the pachytene period was undertaken in an attempt to elucidate the fate of recombination nodules during pachytene and to clarify whether the modification of nodule distribution and the subsequent formation of chiasmata at sites where nodules are present at late pachytene occurs also in the human male, as is the case in Bombyx (9) and Coprinus (12). The objective of this paper, one out of three on the subject, is to illustrate the morphological changes in cytoplasmic and nuclear ultrastructure relevant for dividing the pachytene stage of human spermatogenesis into substages. The subsequent analysis of the placement of recombination nodules and the formation of chiasmata are presented in the two following papers $(10,11)$.

\section{MATERIALS AND METHODS}

\subsection{Materials}

The material is from the same biopsies (cases 1 -5 and a translocation heterozygote $t(5 ; 22))$ as those used in previous studies in this series $(7,8$, 13). Case 1 is an azoospermic man with apparently normal spermatogenesis and cases 2-5 are 
Tables II-VIII.

Synaptonemal complex (SC) length, number of nodules and bars, number of nucleoli and length of the synaptonemal complex between the $X$ and $Y$ chromosomes in human spermatocytes, stages 1 to 7 . a, free nucleoli; b, nucleoli attached to nucleolus organizing regions; sd, standard deviation.

Table II (Stage 1)

\begin{tabular}{|c|c|c|c|c|c|}
\hline \multirow[t]{2}{*}{$\begin{array}{l}\text { Nucleus } \\
\text { number }\end{array}$} & \multirow[t]{2}{*}{$\begin{array}{l}\text { SC length } \\
(\mu \mathrm{m})\end{array}$} & \multirow[t]{2}{*}{$\begin{array}{c}\text { Number of } \\
\text { nodules }\end{array}$} & \multicolumn{2}{|c|}{$\begin{array}{c}\text { Number of } \\
\text { nucleoli }\end{array}$} & \multirow[t]{2}{*}{$\begin{array}{l}\text { SC length } \\
\mathrm{XY}(\mu \mathrm{m})\end{array}$} \\
\hline & & & a & b & \\
\hline 39 & 233 & 91 & 1 & 5 & 1.8 \\
\hline 40 & 212 & 71 & 1 & 5 & 0.5 \\
\hline 41 & 246 & 71 & 3 & 5 & 1.3 \\
\hline 47 & 180 & 80 & 2 & 5 & 1.5 \\
\hline 48 & 216 & 59 & 2 & 5 & 1.0 \\
\hline 49 & 210 & 68 & 3 & 5 & 0.8 \\
\hline 50 & 220 & 75 & 1 & 5 & 0.7 \\
\hline 43 & 202 & 65 & 3 & 5 & 0.7 \\
\hline 44 & 229 & 114 & 1 & 5 & 1.9 \\
\hline 54 & 206 & 40 & 1 & 5 & 0.9 \\
\hline 55 & 227 & 56 & 1 & 5 & 0.8 \\
\hline 56 & 207 & 58 & 0 & 5 & 0.8 \\
\hline 57 & 194 & 59 & 3 & 5 & 1.3 \\
\hline 58 & 184 & 107 & 2 & 5 & $0 c$ \\
\hline 59 & 205 & 99 & 1 & 5 & 0.4 \\
\hline 60 & 212 & 69 & 2 & 5 & 1.6 \\
\hline 61 & 174 & 84 & 0 & 2 & 0.4 \\
\hline 62 & 169 & 57 & 2 & 5 & 1.4 \\
\hline 63 & 165 & 51 & 1 & 5 & Od \\
\hline 64 & 229 & 79 & 3 & 5 & 0.5 \\
\hline 65 & 235 & 110 & 4 & 5 & 0.5 \\
\hline Mean $\pm s$ & $207 \pm 23$ & $75 \pm 20$ & 1.8 & 5.0 & $0.9 \pm 0.5$ \\
\hline
\end{tabular}

c) The short arm of the $Y$ chromosome is deleted.

d) The central region of the synaptonemal complex has not yet attained its normal appearance, the two lateral components being separated by a distance of $150 \mathrm{~nm}$.

normal fertile men. The material consists of 73 completely reconstructed nuclei of which the 21 early pachytene nuclei (stage 1 of the present paper) have been described previously (13). The number of nuclei analysed from each biopsy is given in Table I. With the exception of stage 7 , of which all nuclei came from case 3 , the nuclei of each stage were obtained from two or three different cases.

\subsection{Methods}

The procedure used for fixation, staining, electron microscopy and the subsequent reconstruction of the chromosome complement by its synaptonemal complexes as well as the methods for
Table III (Stage 2).

\begin{tabular}{|c|c|c|c|c|c|c|}
\hline \multirow{3}{*}{$\begin{array}{l}\text { Nucleus } \\
\text { number }\end{array}$} & \multirow{3}{*}{$\begin{array}{c}\text { SC length } \\
(\mu \mathrm{m})\end{array}$} & \multicolumn{2}{|c|}{ Number of } & \multicolumn{3}{|c|}{ Number of SC length } \\
\hline & & nodules & bars & \multicolumn{2}{|c|}{ nucleoli } & \multirow[t]{2}{*}{$X Y(\mu \mathrm{m})$} \\
\hline & & & & a & b & \\
\hline 25 & 227 & 47 & 13 & 6 & 5 & 1.3 \\
\hline 27 & 209 & 47 & 14 & 2 & 4 & 0.2 \\
\hline 28 & 182 & 34 & 10 & 2 & 3 & 1.2 \\
\hline 58 & 203 & 70 & 9 & 2 & 3 & 0.8 \\
\hline 59 & 230 & 78 & 7 & 1 & 4 & 1.0 \\
\hline 60 & 215 & 69 & 11 & 2 & 5 & 0.6 \\
\hline 89 & 224 & 39 & 26 & 3 & 4 & 0.6 \\
\hline 90 & 244 & 76 & 13 & 4 & 4 & 1.2 \\
\hline 91 & 203 & 63 & 25 & 2 & 5 & 0.9 \\
\hline 92 & 215 & 52 & 24 & 1 & 5 & 1.4 \\
\hline 93 & 218 & 58 & 21 & 2 & 4 & 1.2 \\
\hline 94 & 215 & 61 & 14 & 2 & 3 & 1.3 \\
\hline Mean $\pm s d$ & $d 215 \pm 16$ & $58 \pm 16$ & $16 \pm 7$ & 2.4 & 4.1 & $1.0 \pm 0.4$ \\
\hline \multicolumn{7}{|c|}{ Table IV (Stage 3). } \\
\hline \multirow{3}{*}{$\begin{array}{l}\text { Nucleus } \\
\text { number }\end{array}$} & \multirow{3}{*}{$\begin{array}{c}\text { SC length } \\
(\mu \mathrm{m})\end{array}$} & \multirow{3}{*}{\multicolumn{2}{|c|}{$\begin{array}{l}\text { Number of } \\
\text { nodules bars }\end{array}$}} & \multirow{2}{*}{\multicolumn{2}{|c|}{$\begin{array}{c}\text { Number of } \\
\text { nucleoli }\end{array}$}} & $\mathrm{SC}$ length \\
\hline & & & & & & $X Y(\mu \mathrm{m})$ \\
\hline & & & & a & $\mathrm{b}$ & \\
\hline 70 & 234 & 12 & 31 & 0 & 1 & 0 \\
\hline 71 & 256 & 15 & 28 & 0 & 2 & 0 \\
\hline 72 & 256 & 16 & 28 & 0 & 2 & 0 \\
\hline 73 & 238 & 13 & 28 & 1 & 5 & 0 \\
\hline 78 & 252 & 17 & 32 & 1 & 1 & 0 \\
\hline 79 & 221 & 5 & 30 & 0 & 1 & 0 \\
\hline 80 & 233 & 3 & 43 & 0 & 3 & 0.5 \\
\hline 81 & 228 & 9 & 41 & 1 & 4 & 0 \\
\hline 82 & 219 & 13 & 37 & 0 & 4 & 0 \\
\hline 83 & 221 & 9 & 41 & 0 & 3 & 0 \\
\hline 84 & 218 & 10 & 40 & 1 & 4 & 0.4 \\
\hline 85 & 223 & 6 & 41 & 1 & 2 & 0.6 \\
\hline 86 & 241 & 7 & 45 & 0 & 4 & 0 \\
\hline 87 & 234 & 11 & 33 & 0 & 2 & 0.6 \\
\hline 88 & 243 & 19 & 27 & 0 & 4 & 0 \\
\hline Mean $\pm s d$ & d $235 \pm 13$ & $11 \pm 5$ & $35 \pm 6$ & 0.3 & 2.9 & - \\
\hline
\end{tabular}

measuring the synaptonemal complex lengths have been described previously (13).

\section{RESUITS}

\subsection{General organization of the seminiferous tubules}

The general organization of the seminiferous tubules was analyzed in the light microscope with $2.5 \mu \mathrm{m}$ plastic sections of the material fixed for electron microscopy. In several tubules, the histological organization appeared to be disturbed by weak cohesion of the cells since only the spermatogonia, the Sertoli cells and one or two layers of spermatocytes adhered properly while the remaining spermatocytes and sper- 
Table V (Stage 4).

\begin{tabular}{|c|c|c|c|c|c|c|}
\hline \multirow{3}{*}{$\begin{array}{l}\text { Nucleus } \\
\text { number }\end{array}$} & \multirow{3}{*}{$\begin{array}{l}\text { SC length } \\
(\mu \mathrm{m})\end{array}$} & \multicolumn{2}{|c|}{ Number of } & \multicolumn{3}{|c|}{ Number of SC length } \\
\hline & & nodules & bars & nuc & coli & $\mathrm{XY}(\mu \mathrm{m})$ \\
\hline & & & & a & b & \\
\hline 7 & 246 & 14 & 36 & 0 & 1 & 0 \\
\hline 8 & 247 & 6 & 37 & 3 & 0 & 0.3 \\
\hline 9 & 259 & 6 & 36 & 1 & 2 & 0.3 \\
\hline 11 & 222 & 3 & 34 & 0 & 1 & 0 \\
\hline 12 & 219 & 3 & 33 & 0 & 1 & 0 \\
\hline Mean \pm & $239 \pm 17$ & $6 \pm 5$ & $35 \pm 2$ & 0.8 & 0.8 & - \\
\hline
\end{tabular}

Table VI (Stage 5).

\begin{tabular}{|c|c|c|c|c|c|c|}
\hline \multirow{3}{*}{$\begin{array}{l}\text { Nucleus } \\
\text { number }\end{array}$} & \multirow{3}{*}{$\begin{array}{c}\text { SC length } \\
(\mu \mathrm{m})\end{array}$} & \multicolumn{2}{|c|}{ Number of } & \multicolumn{3}{|c|}{ Number of $\mathrm{SC}$ length } \\
\hline & & nodules & bars & nuc & & $\mathrm{XY}(\mu \mathrm{m})$ \\
\hline & & & & a & b & \\
\hline 2 & 239 & 12 & 31 & 0 & 1 & 0 \\
\hline 4 & 225 & 6 & 17 & 1 & 1 & 0.8 \\
\hline 13 & 218 & 7 & 35 & 0 & 1 & 0 \\
\hline 14 & 228 & 3 & 29 & 1 & 1 & 0 \\
\hline 15 & 209 & 3 & 30 & 0 & 1 & 0 \\
\hline 19 & 221 & 3 & 21 & 0 & 1 & 0 \\
\hline 34 & 214 & 13 & 13 & 0 & 1 & 0 \\
\hline 35 & 222 & 9 & 20 & 0 & 1 & 0.1 \\
\hline 36 & 232 & 11 & 18 & 0 & 1 & 1.2 \\
\hline Mean \pm & $223 \pm 9$ & $7 \pm 4$ & $24 \pm 8$ & 0.2 & 1 & - \\
\hline
\end{tabular}

Table VII (Stage 6).

\begin{tabular}{|c|c|c|c|c|c|c|}
\hline \multirow[t]{2}{*}{$\begin{array}{l}\text { Nucleus } \\
\text { number }\end{array}$} & \multirow[t]{2}{*}{$\begin{array}{l}\text { SC length } \\
(\mu \mathrm{m})\end{array}$} & \multirow{2}{*}{\multicolumn{2}{|c|}{$\begin{array}{c}\text { Number of } \\
\text { nodules bars }\end{array}$}} & \multicolumn{3}{|c|}{$\begin{array}{c}\text { Number of SC length } \\
\text { nucleoli } \quad X Y(\mu \mathrm{m})\end{array}$} \\
\hline & & & & a & b & \\
\hline 1 & 244 & 6 & 25 & 1 & 1 & 0 \\
\hline 3 & 262 & 7 & 5 & 0 & 1 & 0 \\
\hline 21 & 221 & 4 & 9 & 0 & 1 & 0.7 \\
\hline 22 & 227 & 5 & 9 & 1 & 0 & 0.7 \\
\hline Mean $\pm s$ & $239 \pm 18$ & $6 \pm 2$ & $12 \pm 9$ & 0.5 & 0.8 & - \\
\hline
\end{tabular}

Table VIII (Stage 7).

\begin{tabular}{ccccccc}
\hline \multirow{2}{*}{$\begin{array}{c}\text { Nucleus } \\
\text { number }\end{array}$} & $\begin{array}{c}\text { SC length } \\
(\mu \mathrm{m})\end{array}$ & \multicolumn{2}{c}{$\begin{array}{c}\text { Number of } \\
\text { nodules }\end{array}$} & bars & \multicolumn{3}{c}{$\begin{array}{c}\text { Number of SC length } \\
\text { nucleoli }\end{array}$} & XY $(\mu \mathrm{m})$ \\
& & & & $\mathrm{a}$ & $\mathrm{b}$ & \\
\hline 23 & 200 & 1 & 3 & 0 & 1 & 0.6 \\
26 & 195 & 4 & 4 & 1 & 0 & 0.5 \\
$\mathbf{4 2}$ & 199 & 1 & 7 & 1 & 0 & 0 \\
$\mathbf{4 3}$ & 182 & 1 & 2 & 1 & 0 & 0.6 \\
$\mathbf{4 4}$ & 186 & 0 & 3 & 0 & 1 & 0.9 \\
$\mathbf{4 5}$ & 194 & 1 & 4 & 1 & 0 & 0.7 \\
$\mathbf{4 6}$ & 230 & 2 & 3 & 0 & 1 & 1.4 \\
\hline Mean \pm sd $198 \pm 16$ & $1 \pm 1$ & $4 \pm 2$ & 0.6 & 0.3 & $0.7 \pm 0.4$ \\
\hline
\end{tabular}

matids were individualized and released into the lumen of the tubule. It is considered unlikely that this disturbance is due to handling or is a fixation artefact as the individual cells in such regions appeared to be as well fixed as those of tubules with normal histology. Individualized spermatocytes at pachytene or later stages were regularly found in the lumen also of tubules with a more intact organization but at a lower frequency. Both categories of cells were excluded from the subsequent electron microscope analysis although several of them appeared intact and morphologically indistinguishable from those present in the epithelium.

In the electron microscope, bi-, and multinucleated cells were frequently found in otherwise normal tubules. As shown in Figure 1, the nuclei of such cells often looked normal and three dimensional reconstruction of three pachytene nuclei (stage 3 , see section 3.5.5.) located in a common cytoplasm were not different from normal cells at the same stage with respect to nuclear fine structure and the number and distribution of recombination nodules. In a few cases, metaphase cells appeared to contain a number of bivalents considerably in excess of the haploid number and it is thus possible that some aneuploid and polyploid spermatids originate from the multinucleated cells.

Virtually all tubules contained a rather high number of degenerating spermatocytes, the majority being at pachytene. The observation of degenerating spermatocytes of different stages in a common cytoplasm (Figure 2) indicates that these clusters are formed by breakdown of intercellular membranes and fusion of the cytoplasms while multicellular groups containing nuclei of similar appearance may have originated either as a result of failure in the for-

Figure 1. Abnormal spermatocytes. Two apparently normal nuclei at stage 3 sharing the same cytoplasm. $\operatorname{Bar}=(2 \mu \mathrm{m})$.

Figure 2. Abnormal spermatocytes. A cytoplasmic syncytium containing 5 nuclei at an intermediate stage of degeneration. The upper two nuclei appear to be at a different stage of development than the three lower ones. $(\mathrm{Bar}=2 \mu \mathrm{m})$. 

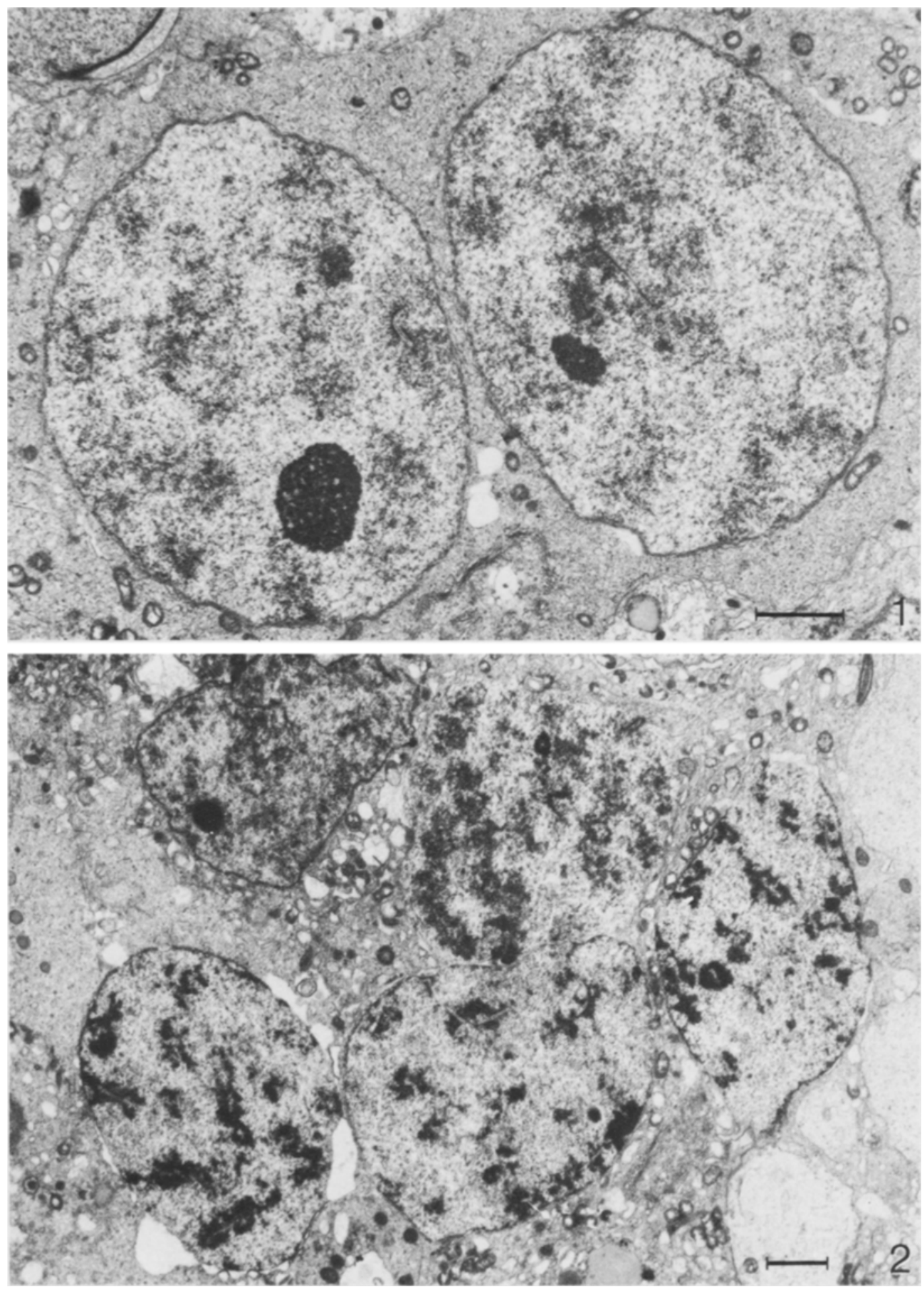

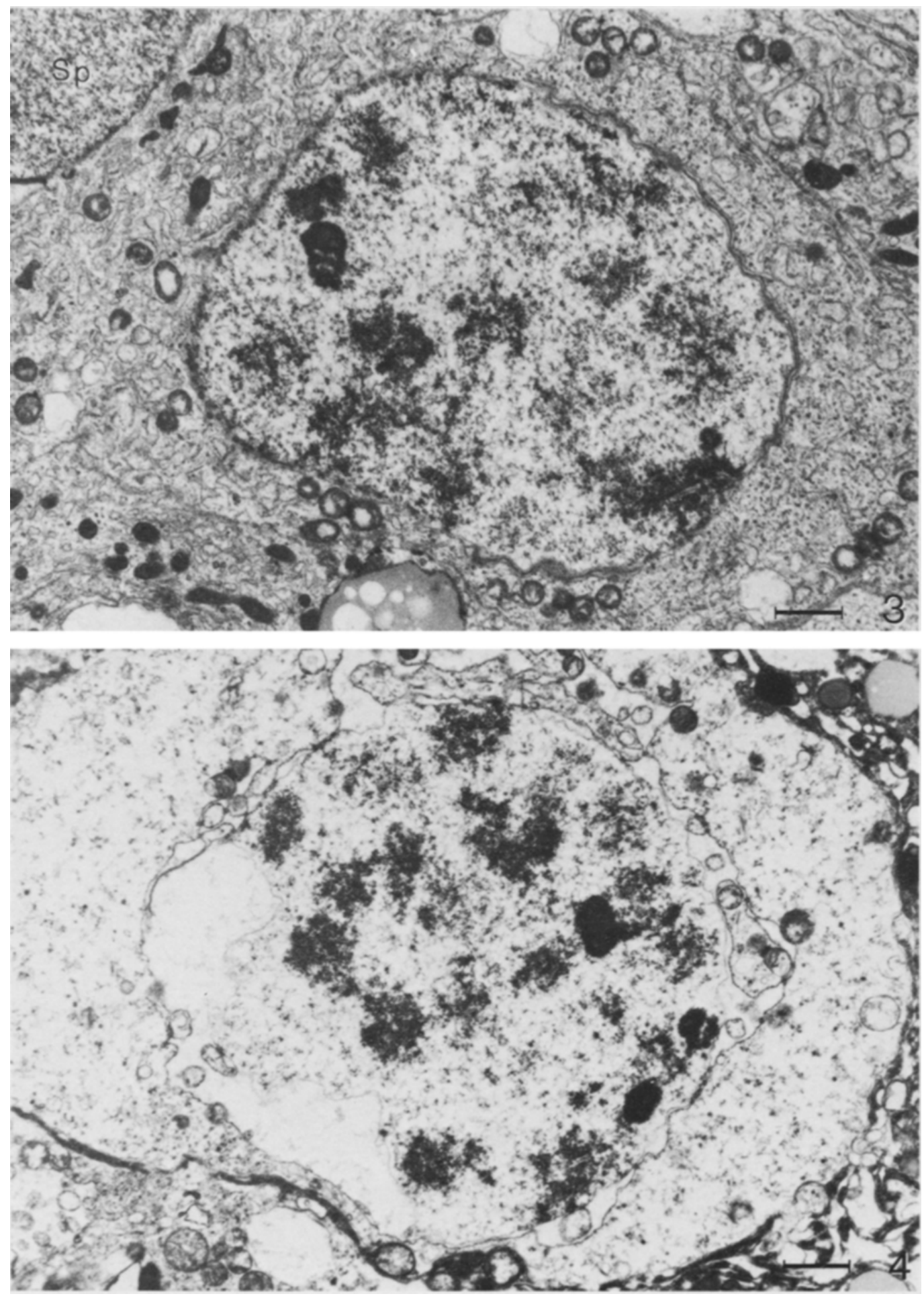
Figure 3. Abnormal spermatocyte. The cytoplasm contains numerous irregular vesicles while the nucleus still appears unaffected. The cell has fused with a spermatid $(\mathrm{Sp})$. $($ Bar $=2 \mu \mathrm{m})$.

Figure 4. Abnormal spermatocyte. Both the cytoplasm and the nucleus are in a progressed state of degeneration. (Bar $=2 \mu \mathrm{m})$.

mation of cell membranes following a previous division or by dissolution of cell membranes between neighbour cells.

Uninucleate cells showing clear signs of degeneration were equally frequent. Such cells were predominantly at pachytene although diplotene and diakinesis and in rare cases also leptotene and zygotene cells were among the degenerating ones. A pachytene cell at an early stage of degeneration appears normal with respect to most nuclear and cytoplasmic characteristics while the chromatin is more electron dense than in normal cells and the cytoplasm contains a large number of small vesicles (Figure 3). The small vesicles originate possibly in part from the disintegrating cell membrane. Pachytene spermatocytes in an advanced state of degeneration (Figure 4) were easily identified by their extremely compact chromatin and the discontinuous nuclear membrane, the inner and outer membrane often being widely separated. Such cells often lack intact cytoplasmic organelles, the cytoplasm instead being filled with numerous vesicles and display a pronounced asynchrony in the development of nuclear structures. It should be noted that in most degenerating nuclei, the integrity of the synaptonemal complex seems to be relatively resistant towards the degradation as shown in Figures 2 and 3 where the synaptonemal complex of the nuclei appears normal with distinct lateral components and central regions.

\subsection{Tetraploid nuclei}

The analysis revealed among normally developing spermatocytes, apparently intact nuclei considerably larger and more electron transparent than pachytene nuclei. The exact frequency of such cells was not determined but they were regularly found in the three biopsies where they were looked for (cases 3-5). Serial sectioning and reconstruction of the lateral component complement of two such nuclei showed that both contained approximately twice the diploid number of chromosomes (89 and 93 chromosomes and chromosome fragments), the total lateral component length amounting to $798 \mu \mathrm{m}$ and $894 \mu \mathrm{m}$ respectively. The latter nucleus (Figures 5 and 6) contained 89 regions of condensed chromatin interpreted as centromere regions. A few chromosomes contained additional condensed regions very similar to the centromere regions while in other cases, the lateral components were discontinuous and/or lacked a centromere region reflecting either yet incomplete organization of the components or chromosome breakage. It is therefore not possible to determine the exact chromosome number. The length of the paired regions in the two nuclei amounted to $7.2 \mu \mathrm{m}$ and $9.1 \mu \mathrm{m}$ and in agreement with the presence of a chromosome bouquet both nuclei were classified as being at early zygotene. In nearly all other aspects the morphology of the nuclei deviates from that of diploid nuclei at the same stage. The noncentromeric chromatin is less condensed while that of the centromere regions is more prominent than in diploid nuclei. The lateral components are distinct and in most cases continuous from telomere to telomere whereas the lateral components of diploid early zygotene nuclei are less distinct and not yet continuous. Finally, the tetraploid nuclei contained one major and several small compact nucleoli while the nucleoli of diploid nuclei at early zygotene are of similar size and have a more open structure. Altogether this shows that the doubling of the chromosome number somehow affects the normal progression of prophase development. It should be noted that the doubling of the chromosome number is accompanied by a twofold increase also of the lateral component length, the mean length of one genome of the tetraploid nuclei amounting to $212 \mu \mathrm{m}$ compared to a length of $235 \mu \mathrm{m}$ for diploid late zygotene nuclei (13). Whether or not such tetraploid nuclei progress through meiosis and give rise to diploid spermatozoa is not known. SASAKI and MAKINO (14) reported that polyploid spermatogonia as well as primary and secondary spermatocytes are present in considerable numbers in the human testis. It is, however, more 


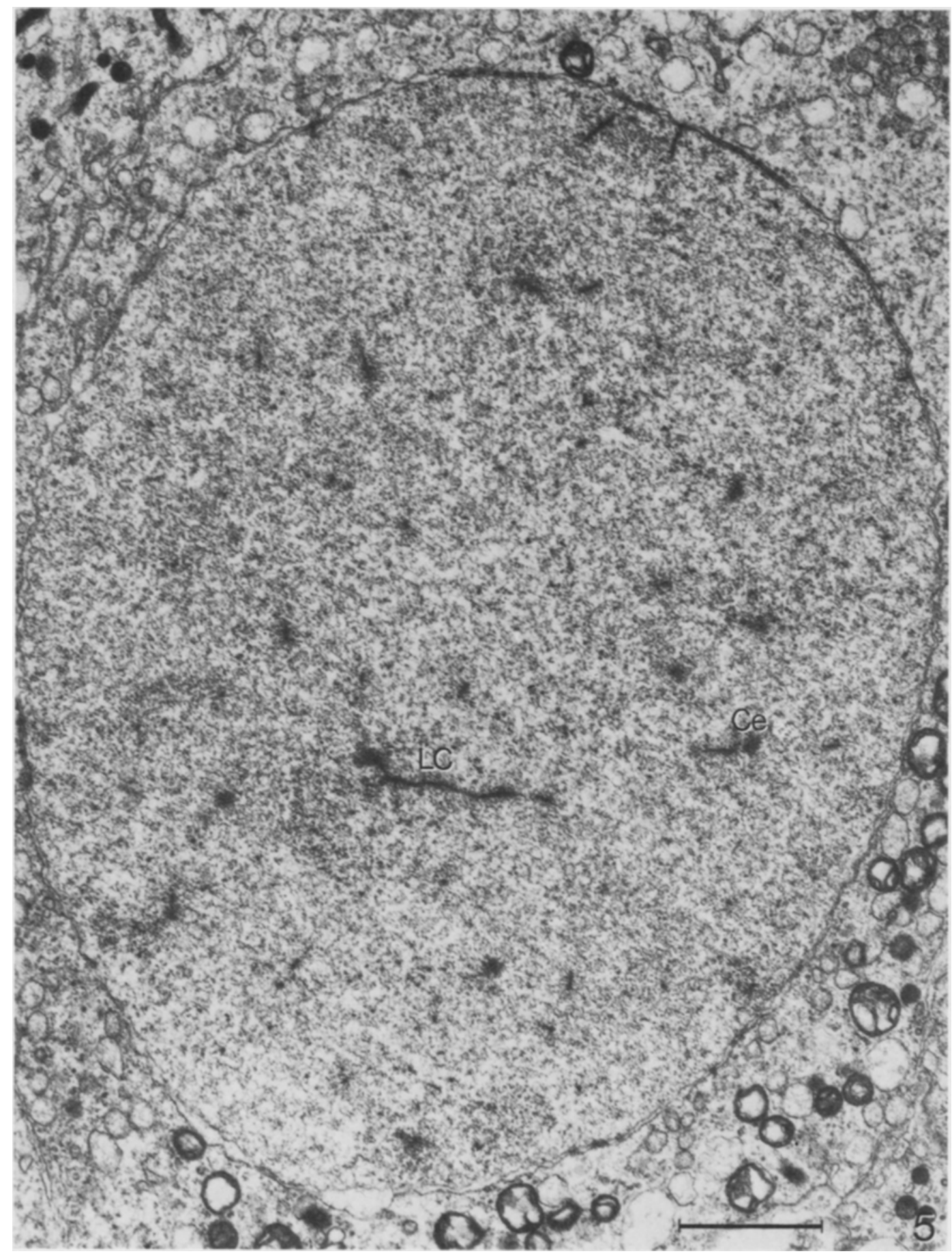

Figure 5. Tetraploid spermatocyte. LC, lateral component. Ce, centromere region. $(\mathrm{Bar}=2 \mu \mathrm{m})$. 

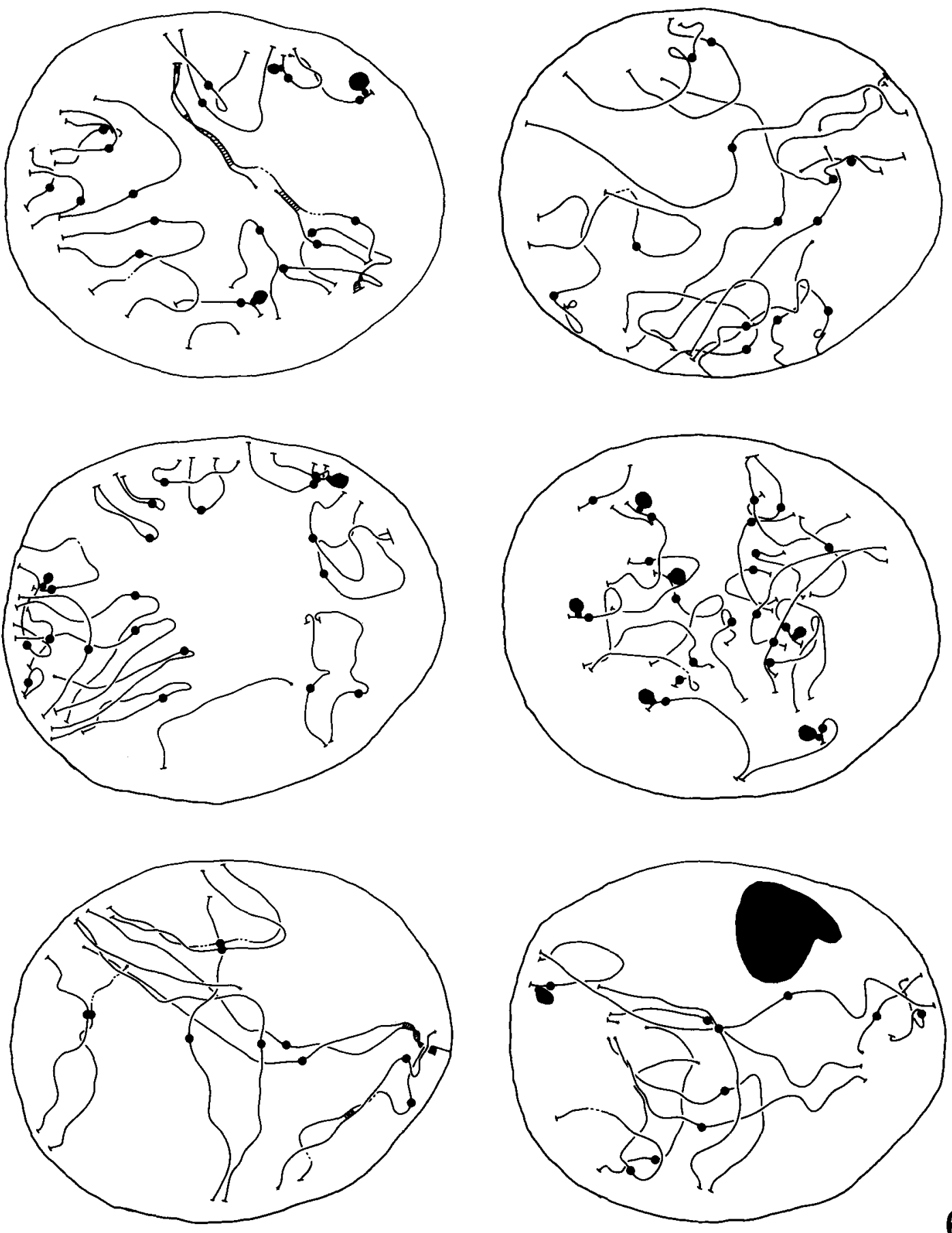

Figure 6. Complete reconstruction of the tetraploid nucleus shown in Figure 5. The cross bars denote the attachment sites of the telomeres on the nuclear envelope, the stars mark telomeres or broken chromosome ends not attached to the envelope, the larger filled circles are the centromere regions $(n=89)$ and the smaller ones the nucleolus organizer regions $(n=12)$. Nucleoli are shown as solid black patches. 
likely that the majority of the apparently polyploid spermatocytes were bi- and multinucleate rather than polyploid since only bivalents were observed at metaphase I. Polyploid spermatocytes appear to be rare in other mammals as well and only in few cases have multivalents been reported (16).

\subsection{An electron microscope atlas of the seven pachytene substages}

In an attempt to provide a well-defined set of criteria for a reproducible subdivision of the pachytene stage, the following nuclear structures were chosen as primary markers for the identification of the individual stages. (A) the centrioles, (B) the chromatin, (C) the XY bivalent, (D) the centromere region, (E) the nucleoli and (F) the secondary constriction on bivalents 1, 9 and 16. The appearance of each of these structures is shown in single micrographs or in short series for each of the substages and the relevant structural details are described in sections 3.3.2 3.3.9. This information is supplemented by descriptions of stage-typical features not covered by the schematic presentation. Finally, the Tables II-VIII include the quantitative information for each of the 73 reconstructed nuclei. The appearance of the selected marker structures at late zygotene and early diplotene has been included in order to establish the morphology of human spermatocyte nuclei prior to and after the pachytene stage.

\subsubsection{Late zygotene}

Per definition, the late zygotene nuclei are characterized by a nearly complete pairing and synaptonemal complex formation in all bivalents. Furthermore, a chromosome bouquet is always a characteristic of this stage. The six marker parameters exhibit the following morphological features (cf. Figure 8): (A) The size of the procentriole is about 25 percent of the mother centriole. (B) The chromatin is dispersed and evenly distributed throughout the nucleus. (C) The chromatin of the XY bivalent is very similar to that of the autosomes and both sex chromosomes have continuous lateral components. The distal regions of the short arms are in some nuclei paired with a synaptonemal complex. (D) The chromatin of the centromere forms a small con- densed sphere approximately $0.25 \mu \mathrm{m}$ in diameter. (E) All acrocentric bivalents are associated with irregularly shaped nucleoli displaying a nucleolonema. At this as well as at all the subsequent pachytene stages, the association between the nucleolus and the bivalent is mediated by a fibrillar body. $(F)$ The secondary constriction on bivalents 1,9 and 16 is in most cases unpaired with discontinuous lateral components, the chromatin having a higher density than paracentromeric chromatin of other bivalents.

\subsubsection{Stage 1 (early pachytene)}

The entrance into pachytene is marked by completion of synaptonemal complex formation, the only unpaired regions being those of the secondary constrictions and the differential segments of the $\mathrm{X}$ and $\mathrm{Y}$ chromosomes. In addition to a pronounced bouquet the first substage of pachytene is characterized by the following features (see also Figures 7 and 9 and Table II): (A) The relative sizes of the pro- and mother centrioles are as in late zygotene. (B) The chromatin is slightly condensed around the synaptonemal complex. (C) The chromatin of the $\mathrm{X}$ and $\mathrm{Y}$ chromosomes forms a well-defined compact body distinctly different from the autosomal chromatin. The lateral components are continuous with a diameter larger than that of the autosomes. The distal parts of the short arms are always paired with a short segment of synaptonemal complex. (D) The centromeric chromatin consists of a nearly spherical central condensation surrounded by a region of less compacted chromatin. (E) The irregularly shaped nucleoli are composed of an extensive nucleolonema, i.e., a network of electron transparent cavities in a matrix of high electron density. (F) During this stage, synaptonemal complex formation is completed in the regions of the secondary constrictions and the stage thus includes nuclei with paired as well as with unpaired secondary constrictions. Morphologically, these regions differ from the remaining paracentromeric regions only by their larger amount of compacted chromatin, and in some cases by yet discontinuous lateral components.

\subsubsection{Stage 2 (early pachytene)}

During this stage the chromosome bouquet is 

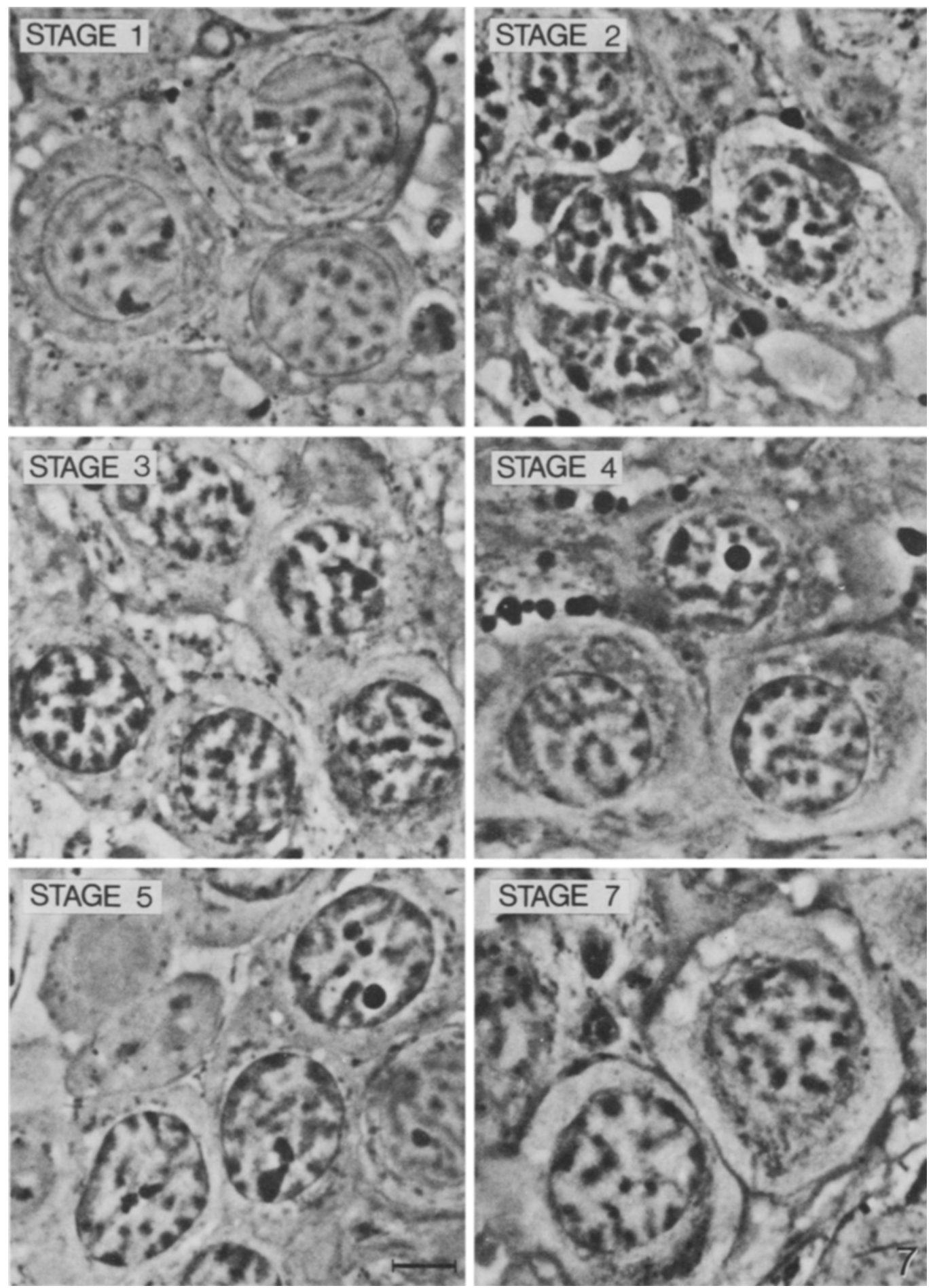

Figure 7. Light microscope pictures of sections of pachytene cells at stages $1-5$ and 7. (Bar $=5 \mu \mathrm{m})$. 
resolved and as a consequence varying degrees of polarity of chromosome attachment sites on the nuclear envelope are encountered among the nuclei allocated to this stage. The transport of the attached telomere regions during the resolution of the bouquet is accompanied by formation of large invaginations of the inner nuclear membrane. The stage typical appearance of the markers are as follows (see also Figures 7 and 10 and Table III): (A) The size and shape of the duplicating centriole is similar to that of late zygotene nuclei. (B) The bivalents are readily recognizable by their chromatin contour, which also outlines the chromomeres. The degree of chromatin condensation is uniform along the length of the bivalents and higher than at stage 1 . (C) The fine structure of the $\mathrm{XY}$ bivalent is similar to that of stage 1 and the distal part of the short arms is always paired into a synaptonemal complex. (D) The chromatin of the centromere region is more compact than that of the flanking bivalent regions, the outline of the centromere region being irregular. (E) The shape of the nucleoli is fairly rounded but otherwise as in stage 1 . The centromere region on the acrocentric bivalents is larger and more condensed than that of the remaining bivalents. (F) The secondary constriction on bivalent 1,9 and 16 is now completely paired and can only be identified by its larger amount of compacted chromatin.

\subsubsection{Stage 3 (mid pachytene)}

This stage is characterized by the following features (see also Figures 7 and 11 and Table IV): (A) The procentriole is about half the size of the mother centriole. (B) The chromatin exhibits along the length of the bivalents a distinct chromomere pattern, regions of less chromatin alternating with more chromatin containing regions. (C) The XY bivalent has changed drastically in structure. The lateral components of the $\mathrm{X}$ and $Y$ chromosomes are split longitudinally and are branched in several places. The four telomeres are attached in the vicinity of each other but in most nuclei only remnants of a synaptonemal complex segment can be recognized. (D) The dense centromeric chromatin forms a spherical mass around or lateral to the synaptonemal complex. (E) The morphology of the nucleoli changes towards the end of this stage from the early pachytene type with a nucleolonema structure to the compact and spherical mid-late pachytene type which generally contains a round body of high electron density - the dark body. The chromatin of the centromere region and the short arm of the acrocentric bivalents are compact and form a confluent mass. (F) The chromatin of the secondary constriction is at this stage organized as an open matrix containing a number of compact knots with irregular outline. The synaptonemal complex passes unaffected through the dimorphic region and the associated centromere region.

\subsubsection{Stage 4 (mid pachytene)}

The distinguishing features of this stage are as follows (see also Figures 7 and 12 and Table V): (A) The size of the procentriole is as in stage 3. (B) The chromomere structure has again become less distinct apparently caused by unravelling of chromatin domains initiated by the end of stage 2. During stage 4 compact knobs appear on some of the autosomal bivalents. (C) The morphology of the XY bivalent is similar to that at stage 3 . (D) The centromere associated chromatin is uniformly compacted and of higher electron density than at stage 3. (E) The nucleoli are spherical, contain a round dark body and are without electron transparent cavities. Generally, only one of the five acrocentric bivalents is associated with a nucleolus. Frequently, free nucleoli of similar structure are present in the nucleoplasm. (F) The secondary constrictions are similar to those at stage 3.

\subsubsection{Stage 5 (late pachytene)}

The beginning of late pachytene is marked by the following characteristics of the structures used for classification (see also Figures 7, 13 and 14 and Table VI): (A) The procentriole is about 75 per cent of the size of the mother centriole. (B) The chromatin is similar to that of stage 4 with some compact domains. Knobs are prominent and may in some cases be as large as the centromere region. This produces together with the dense centromeric chromatin a characteristic lumpy appearance of the bivalents. (C) The morphology of the XY bivalent is as in stages 3 and 4 . (D) During this stage, a region of medium electron density develops in the condensed chro- 

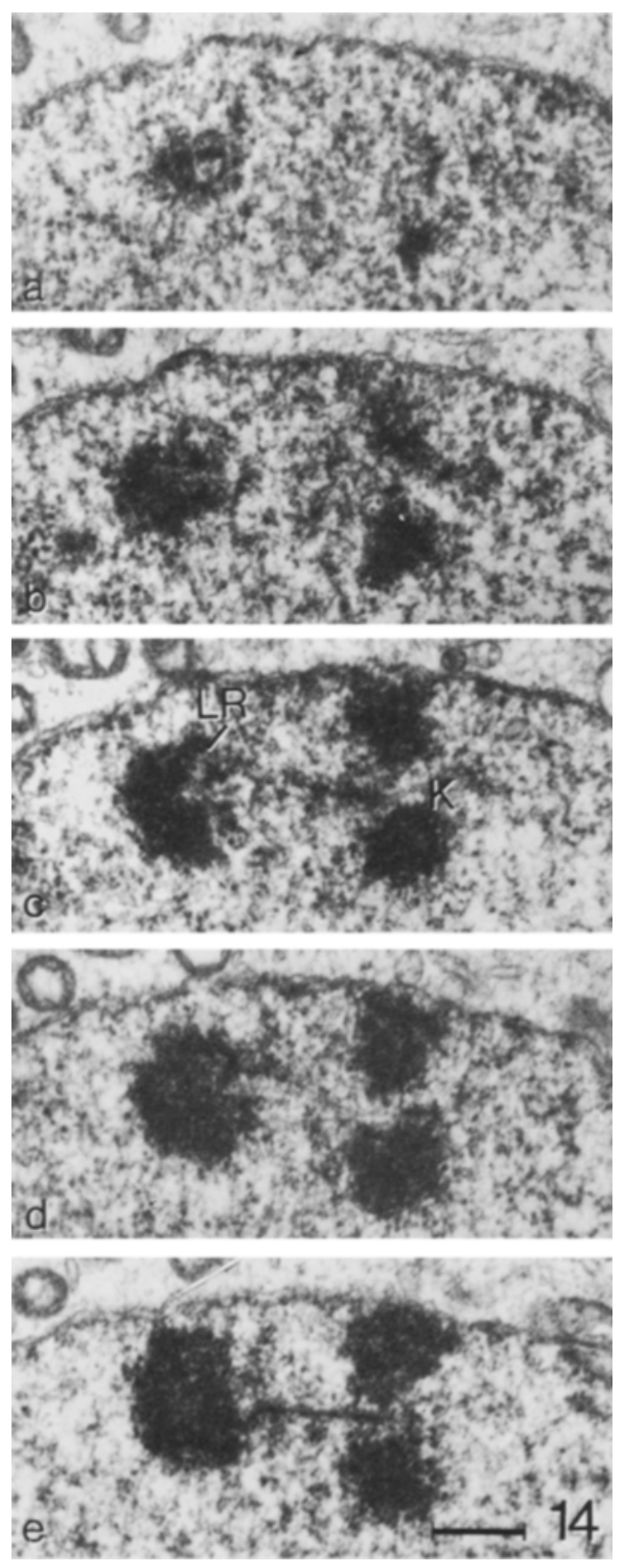

Figure 14. Five consequtive sections through a centromere region $(\mathrm{Ce})$ and a proximal $\mathrm{knob}(\mathrm{K})$ in a nucleus at stage 5 . Note that only the centromere region contains a light region (LR). (Bar $=0.5 \mu \mathrm{m})$.

matin of the centromere. (E) The nucleoli are often smaller but otherwise indistinguishable from those seen at stage 4 . The confluent chro- matin of the centromere region and the short arm of the acrocentric bivalents is uniformly compacted and of high electron density. (F) The morphology of the dimorphic chromatin of the secondary constrictions is as in stages 3 and 4 .

\subsubsection{Stage 6 (late pachytene)}

It is not possible by precise morphological criteria to define the transition between stages 5 and 6. The overall appearance of nuclei allocated to this stage differs from that of stages 5 and 7 mostly by a more diffuse chromatin outline while the remaining parameters are not distinctly different from that of the bordering stages. A possible marker for the initiation of stage 6 is the disappearance of the typical dimorphic organization of the secondary constriction on bivalents $I$ and 16 while that on bivalent 9 remains. The subsequent analysis of the number and distribution of recombination nodules and bars (12) did, however, justify the interpretation that these nuclei represent a separate phase of the pachytene development, namely the period in which the recombination bars disappear from the synaptonemal complexes.

\subsubsection{Stage 7 (late pachytene)}

The typical features of this stage are the following (see also Figures 7 and 15 and Table VIII): (A) The centriolar duplication is complete or nearly so, the size of the mother and daughter centrioles being almost the same. (B) The lumpy appearance of the chromatin observed at stage 5 is now pronounced, large irregular lumps of condensed centromeric chromatin and knobs alternating with regions of diffusely outlined chromatin. (C) The lateral components of the sex chromosomes are now continuous over long stretches and the entire $\mathrm{Y}$ chromosome can be reconstructed. In most nuclei a distinct synaptonemal complex segment can be seen between the distal parts of the short arms. (D) The centromeric chromatin has attained its maximum compaction and contains a distinct light region intimately associated with the synaptonemal complex. (E) The nucleoli are smaller and fewer than at stage 5 and layers or lacunae of fibers of intermediate density, possibly a part of the fibrillar body, are present inside the free as well as the bivalent associated nucleoli.(F) As described for 
stage 6 , a secondary constriction with dimorphic structure is only present on bivalent 9 .

\subsubsection{Early diplotene}

The initiation of synaptonemal complex elimination marks the end of the pachytene stage. The shedding of the synaptonemal complex from the bivalents is accompanied by the following characteristics of the selected structures (see also Figure 16): (A) The duplication of the centrioles is complete. (B) The chromatin is uniformly structured except for a few regions of more condensed chromatin resulting in a relatively well-defined appearance of the bivalents in the micrographs. (C) The organization of the XY bivalent is at the beginning of the substage similar to that at stage 7 while the morphology of the chromatin by the end of early diplotene approaches that of the autosomes. During the whole period the lateral components of the sex chromosomes are discontinuous while the short segment of synaptonemal complex remains in most nuclei. (D) The centromere region contains two separate or one bipartite condensed region surrounding a sphere of medium dense fibers, the prokinetochores. (E) The single spherical nucleolus is always free in the nucleoplasm. $(\mathrm{F})$ The typical dimorphic condensation pattern of the secondary constriction is present on bivalent 9 only.

A more detailed description of this and later stages is given in a following publication (11).

\section{DISCUSSION}

\subsection{Cellular degeneration}

As described in section 3 an ultrastructural analysis of the pachytene stage in human spermatocytes is not straightforward. Several tubules in the testes of normal fertile men appear partially defective due to weak cell cohesion and massive degeneration of cells, in particular at the pachytene stage. Even in well-organized tubules, a considerable number of nuclei degenerate during the meiotic prophase which introduces a certain degree of ambiguity in identifying representatives of the normal sequence. In most cases, the morphological symptoms of degeneration are readily observable in sectioned material and such nuclei can be avoided. There are, however, pachytene nuclei of almost normal morphology which appear to be at an initial stage of degeneration as recognized by partial fragmentation of cytoplasmic membranes. Although such cells may not complete the meiotic prophase, it is considered unlikely that they affect the sequence of pachytene stages if they were included.

The observations presented in section 3.3. reveal a continuous series of changes in nuclear architecture from late zygotene to early diplotene and it seems reasonable to conclude that the developmental sequence, based on reconstructions of the 73 nuclei covers the entire pachytene period of human spermatogenesis.

\subsection{The course of the pachytene stage}

The ultrastructural changes in nuclear morphology during pachytene have been described in several papers $(1,2,7,16,17,18,19)$ and the following discussion will therefore concentrate upon aspects not adequately accounted for by previous investigations.

Chromatin: In a previous publication (7) we assumed that progressive condensation of the chromatin occurred during the pachytene stage. In contrast SolarI and Tres $(17,18)$ and SolarI (15) argued that the chromatin decondensed throughout pachytene eventually resulting in a diffuse diplotene stage. Neither of these proposals for the pattern of chromatin condensation in man are in agreement with the present observations. The general trend from late zygotene onwards is that the centromeric chromatin increases in compactness during pachytene while the chromatin of the bivalent arms undergoes a series of changes: From stage 1 to 3 the chromomeres become more distinctly outlined, whereafter the chromomere organization again becomes less distinct. From stage 5 to stage 7 some regions of the bivalents develop large dense knobs. The transition to diplotene is characterized by the establishment of a uniform distribution of the chromatin along the bivalents.

Nucleoli: The two major features of the nucleolar development are a progressive reduction in total number of chromosome associated nucleoli from a mean of 5 per nucleus at stage 1 to 0.3 at stage 7 , and a change in structure and shape from the early pachytene type with a nucleolonema to the solid dense sphere of late 
pachytene nuclei. The chromatin of the centromere region and that of the short arms of the acrocentric bivalents condenses during pachytene and fuses into a confluent chromatin mass. This sequence of changes in nucleolar morphology is similar to that reported by TRES (19).

$X Y$ bivalent: As described in section 3.3. and in Tables II to VIII, the $\mathrm{X}$ and $\mathrm{Y}$ chromosomes pair and form a synaptonemal complex by the end of zygotene in all nuclei. The length of the synaptonemal complex segment then remains constant through stages 1 and 2 of pachytene. By stage 3 the synaptonemal complex segment disappears in most nuclei concomitantly with the modification of the lateral components. The morphology of the XY bivalent remains constant through stages 4, 5 and 6 until lateral component continuity is almost reestablished at stage 7. Simultaneously, a segment of synaptonemal complex reappears between the homologous regions of the sex chromosomes. It is thus conceivable that the modification of the lateral components and the change in the filamentous substructure of the XY bivalent at stage 3 also affects the synaptonemal complex causing a loss of its distinct tripartite structure, as a structurally normal synaptonemal complex segment reappears at stage 7 where the morphology of the XY bivalent reverts to an early pachytene-like type. Other investigations $(16,17)$ have suggested a progressive reduction in length of the synaptonemal complex segment and its permanent disappearance as the XY bivalent is modified. These discrepancies can be attributed to the lack of information on XY bivalent structure at the pachytene-diplotene transition and insufficient criteria for staging nuclei at early pachytene in previous investigations.

\subsection{Subdivision of the pachytene stage}

It should be emphasized that the present subdivision of the pachytene although feasible with a high degree of precision for nuclei in the middle of the substages, is more ambiguous at the beginning and the end of each substage. However, the analysis shows that it is possible to divide the 16 day pachytene stage of human spermatogenesis (6) into seven substages on the basis of a combination of 5 nuclear structures, the size of the procentrioles and the presence of a chromosome bouquet.

In agreement with this, the changes in the number of recombination nodules and bars in nuclei arranged according to the above criteria form a simple interpretable pattern. The total number of recombination nodules decreases gradually from 75 at stage 1 to only one at stage 7 while the recombination bars appear at stage 2 , reach a maximum of 35 at stages 3 and 4 and disappear during stages 5 to 7 . The appearance of recombination bars coincides with the disappearance of nodules in numbers which make the conversion of nodules into bars conceivable.

The present subdivision of the pachytene stage in the human male is more detailed but otherwise consistent with the subdivision proposed by BERTHELSEN et al. (2) who distinguished between early, mid and late pachytene by criteria which in the present work have been used to characterize stages 1-2, 3-4 and 5-7, respectively. A subdivision into five stages has been proposed by SolARI (16) in an analysis of the number and distribution of recombination bars in microspread preparations of pachytene nuclei. His classification is based primarily on a distinction between five characteristic types of XY bivalents: Type 1 includes $X Y$ bivalents with continuous lateral components and a synaptonemal complex segment between the homologous regions. Type 2 $X Y$ bivalents differ from type 1 by a splitting of the lateral components, by the presence of excrescences from the lateral components and by having a shorter synaptonemal complex segment. The secondary constriction on bivalents 1 and 9 is often unpaired and the largest number of nucleoli are present in nuclei containing $X Y$ bivalents of types 1 and 2. XY bivalents of type 3 exhibit extensive splitting of the lateral components and are either without a synaptonemal complex segment or contain only a short stretch. The XY bivalents of type 4 contain two or three large bodies which in $\mathrm{XY}$ bivalents classified as type 5 have broken down into 10-20 smaller particles. In nuclei containing XY bivalents of the latter two types, the nucleoli often possess an inner dense body.

A direct comparison between the classification scheme proposed by SoLARI and that reported in the present paper is met with difficulties. Nuclei 
with $\mathrm{XY}$ bivalents of types 1 and 2 described by SolarI obviously correspond to nuclei at stages 1 or 2 and nuclei with XY morphology of types 3-5 belong to stages 3-6 in the present investigation. Two major discrepancies are, however, evident when the two arrays of pachytene nuclei are compared: Solari failed to detect the reappearance of a synaptonemal complex segment between the $\mathrm{X}$ and $\mathrm{Y}$ chromosomes toward the end of pachytene. Secondly, the number of recombination bars was reported to be constant throughout pachytene (the mean number being $46 \pm 8$ ) in the microspread material while the present investigation disclosed a distinct pattern of changes in total number of nodules and bars during pachytene. These discrepancies are discussed in detail in the following paper.

\section{ACKNOWLEDGEMENTS}

We would like to thank D. voN WETTSTEIN for his critical review of the manuscript. The expert assistance of JEAN SAGE is gratefully appreciated. The work was supported by grants BIO-E-417 $D K(G)$ from the Commmission of the European Communities to D. von WeTtSTEIN and by a Niels Bohr scholarship from the Royal Danish Academy of Sciences and Letters to PrebeN BACH HOLM.

\section{REFERENCES}

1. Berthelsen, J.G., M.Fegh \& N.E. SkakKEBAK: Electron microscopic analysis of meiotic chromosomes from human spermatocytes during and after treatment with steroid hormones. Carlsberg Res. Commun. 46, 9-23 (1980)

2. Berthelsen, J.G. \& N.E. SKakkebek: Ultrastructure of meiotic chromosomes in boys undergoing chemotherapy for leukemia. Leuk. Res. (in press)

3. Carpenter, A.T.C: Electron microscopy of meiosis in Drosophila melanogaster II. The recombination nodule - a recombination associated structure at pachytene? Proc. Nat. Acad. Sci. USA 72, 3186-3189 (1975)

4. CARPenter, A.T.C.: Synaptonemal complex and recombination nodules in wild type Drosophila melanogaster females. Genetics 92, 511541 (1979)

5. Carpenter, A.T.C.: Synaptonemal complex and recombination nodules in recombination deficient mutants of Drosophila melanogaster. Chromosoma (Berl.) 75, 259-292 (1979)

6. Heller, C.G. \& Y. Clermont: Kinetics of the germinal epithelium in man. Recent Prog. Horm. Res. 20, 545-575 (1964)

7. Holm, P.B. \& S.W. Rasmussen: Human meiosis I. The human pachytene karyotype analyzed by three dimensional reconstructions of the synaptonemal complex. Carlsberg Res. Commun. 42, 283-323 (1977)

8. Holm, P.B. \& S.W. Rasmussen: Human meiosis III. Electron microscopical analysis of chromosome pairing in an individual with a balanced translocation 46,XY,t(5p-;22p+). Carlsberg Res. Commun. 43, 329-350 (1978)

9. Holm, P.B. \& S.W. Rasmussen: Chromosome pairing, recombination nodules and chiasma formation in diploid Bombyx males. Carlsberg Res. Commun. 45, 483-548 (1981)

10. Holm. P.B. \& S.W. Rasmussen: Human meiosis VI. Crossing over in human spermatocytes. Carlsberg Res. Commun. 48, 385413 (1983)

11. Holm, P.B. \& S.W. Rasmussen: Human meiosis VII. Chiasma formation in human spermatocytes. Carlsberg Res. Commun. 48, 415-456 (1983)

12. Holm, P.B., S.W. RasmusSen, D. ZickLer, B.C. LU \& J. SAGE: Chromosome pairing, recombination nodules and chiasma formation in the basidiomycete Coprinus cinereus. Carlsberg Res. Commun. 46, 305-346 (1981)

13. Rasmussen, S.W. \& P.B. Holm: Human meiosis II. Chromosome pairing and recombination nodules in human spermatocytes. Carlsberg Res. Commun. 43, 275-327 (1978)

14. SASAKI, M. \& S. MAKINO: The meiotic chromosomes of man. Chromosoma (Berl.) 16, 637. 651 (1965)

15. Solari, A.J. \& M.J. Moses: Synaptonemal complexes in a tetraploid mouse spermatocyte. Exptl. Cell Res. 108, 464-467 (1977)

16. SoLARI, A.J.: Synaptonemal complexes and associated structures in microspread human spermatocytes. Chromosoma (Berl.) 81, 315337 (1980)

17. Solari, A.J. \& L.L. TREs: The three dimensional reconstruction of the $X Y$ chromosomal pair in human spermatocytes. J. Cell Biol. 45, 43-53 (1970)

18. Solari, A.J. \& L.L. Tres: Ultrastructure and histochemistry of the nucleolus during male meiotic prophase. In: The Human Testis, E. Rosenberg and C. Paulson, eds. Plenum Press, New York, pp 127-138 (1970) 
P.B. Holm \& S.W. RasmuSSEN: Human meiosis V

19. TRES, L.L.: Nucleolar RNA synthesis of meiotic prophase spermatocytes in the human testis. Chromosoma (Berl.) 53, 141-151 (1975) 

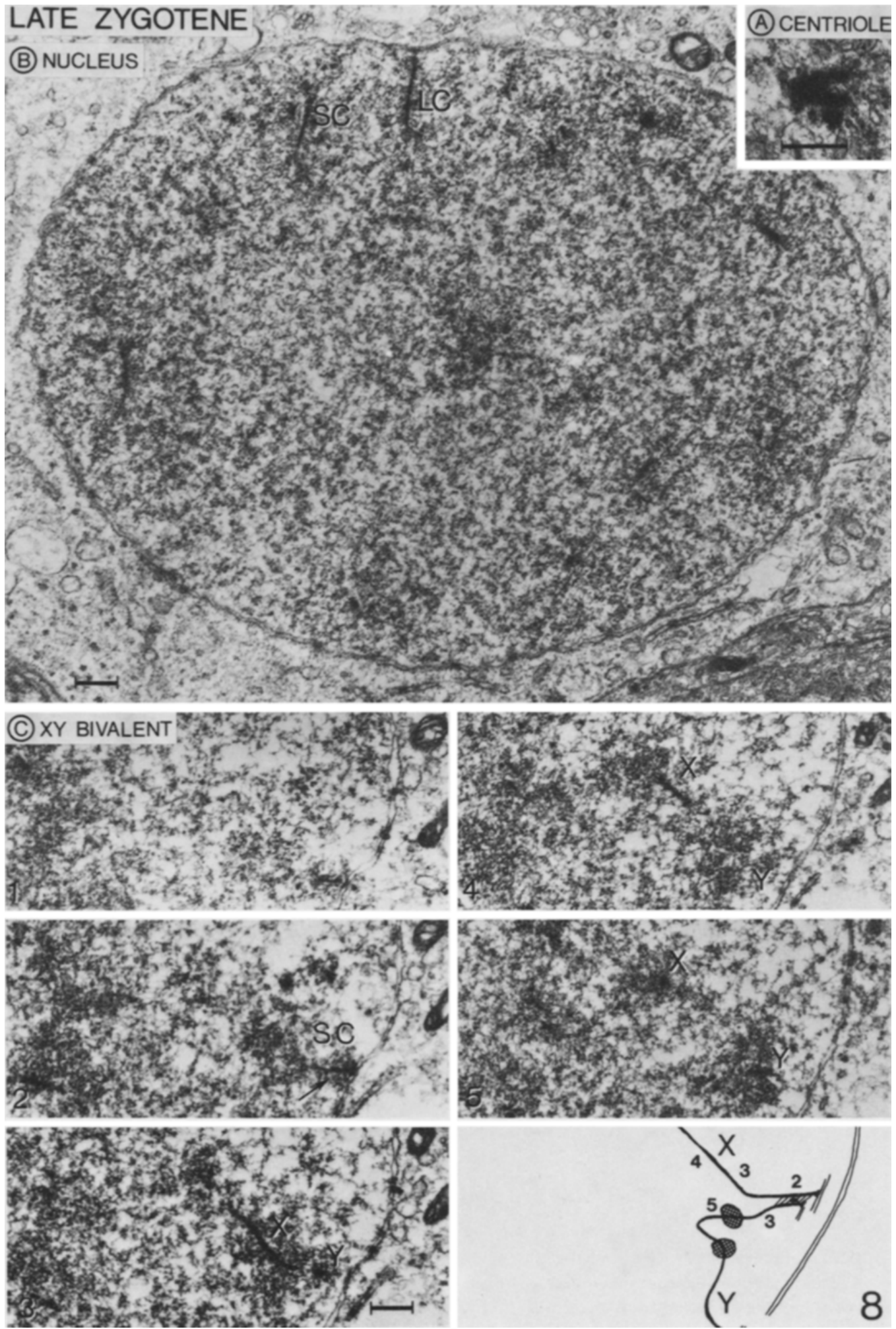

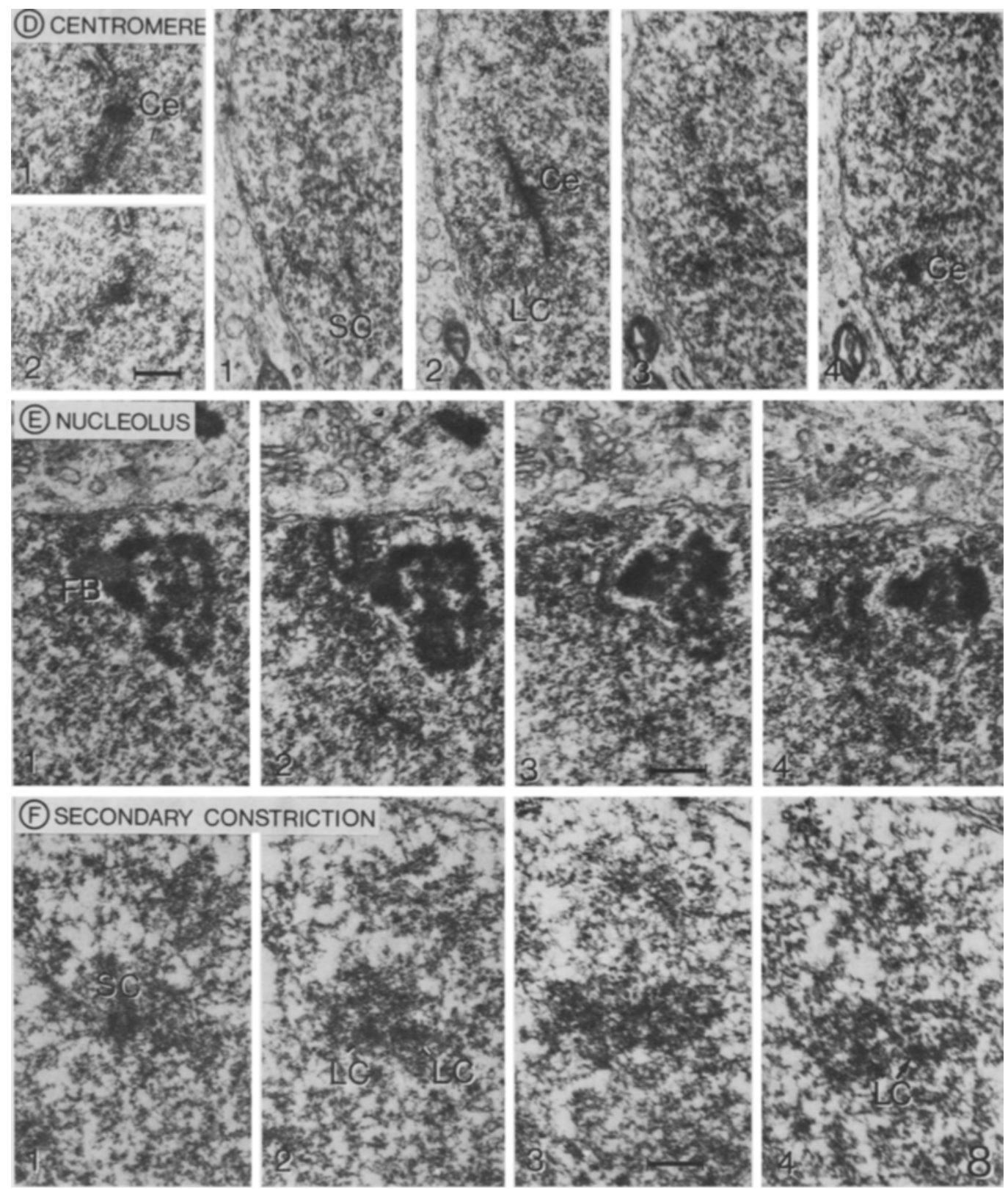

Figure 8. Late zygotene. SC, synaptonemal complex. LC, lateral component. FB, fibrillar body mediating the association between the bivalent and the nucleolus. $\mathrm{X}, \mathrm{X}$ chromosome. $\mathrm{Y}, \mathrm{Y}$ chromosome, arrow denotes a recombination nodule. $\mathrm{Ce}$, centromere region in paired (left) and unpaired (right) lateral component segments. The secondary constriction is from bivalent 16 . Note that the lateral components are discontinuous on section 3 . The numbers are the relative section numbers for the short series of consecutive sections. (Bars $=0.5 \mu \mathrm{m}$ ). 

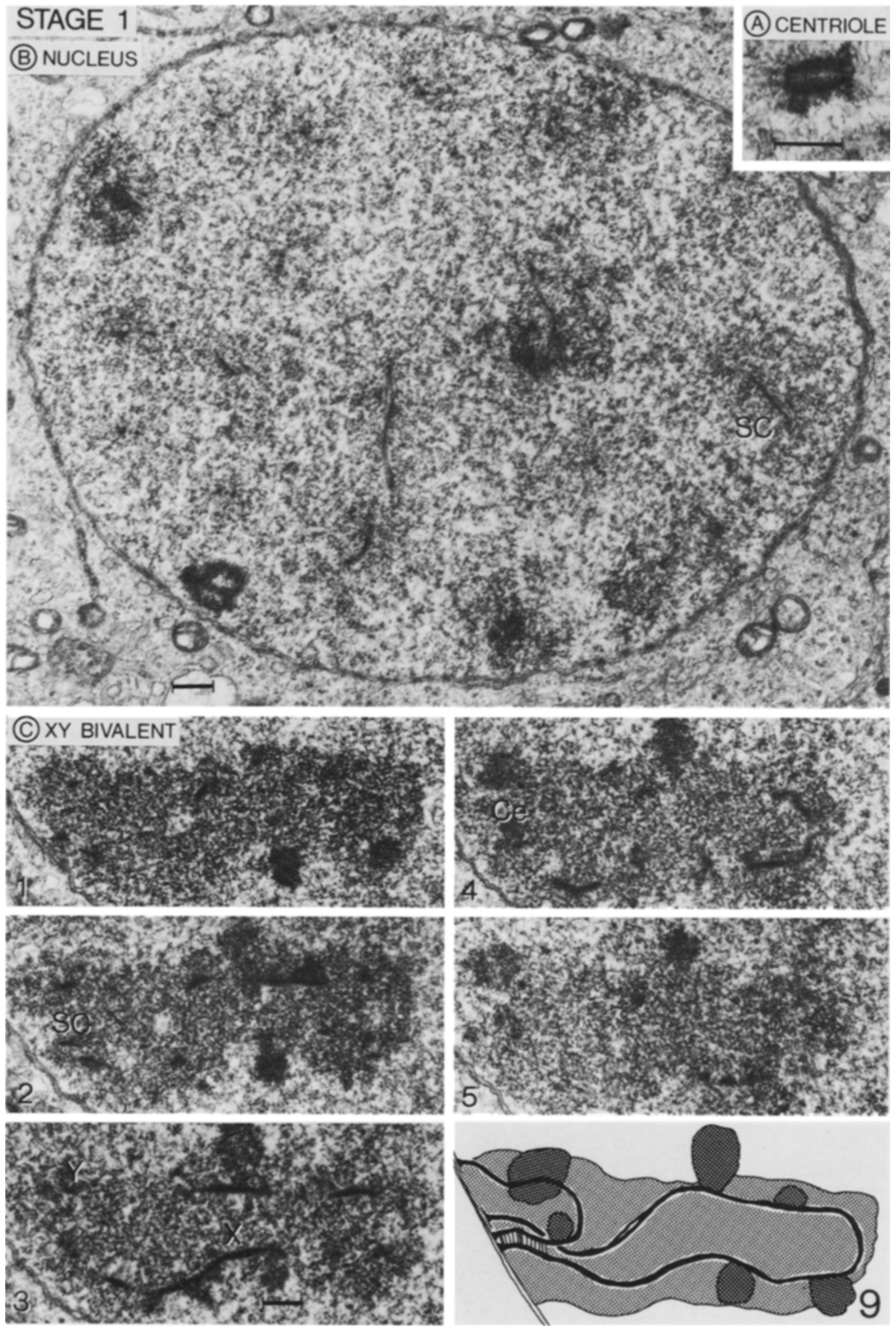

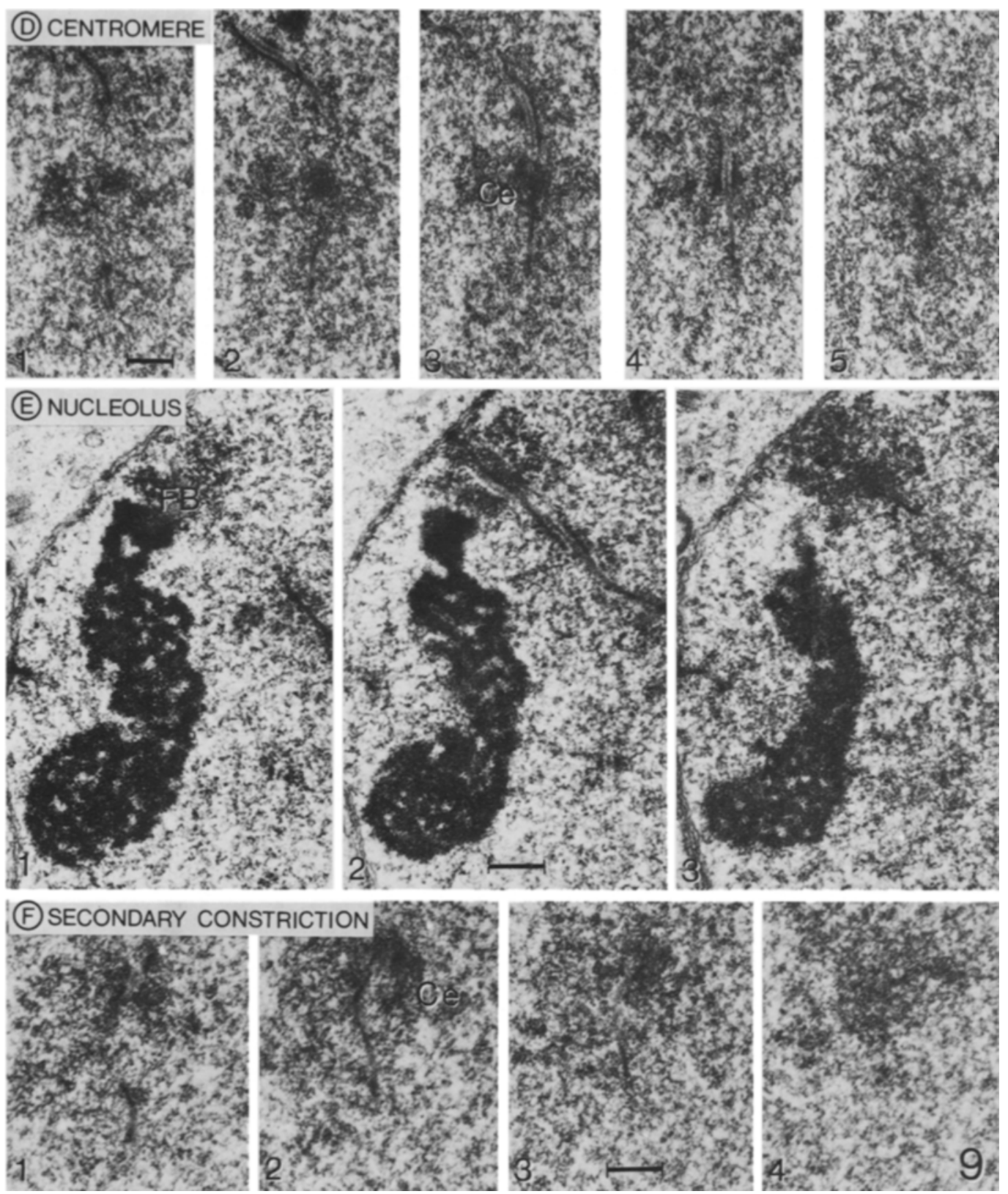

Figure 9. Stage 1 (early pachytene). SC, synaptonemal complex. LC, lateral component. Ce, centromere region. FB, fibrillar body. $\mathrm{X}, \mathrm{X}$ chromosome. $\mathrm{Y}, \mathrm{Y}$ chromosome. One of the lateral components in the secondary constriction of bivalent 1 is discontinuous. The numbers are the relative section numbers for the short series of consecutive sections. (Bars $=0.5 \mu \mathrm{m})$. 

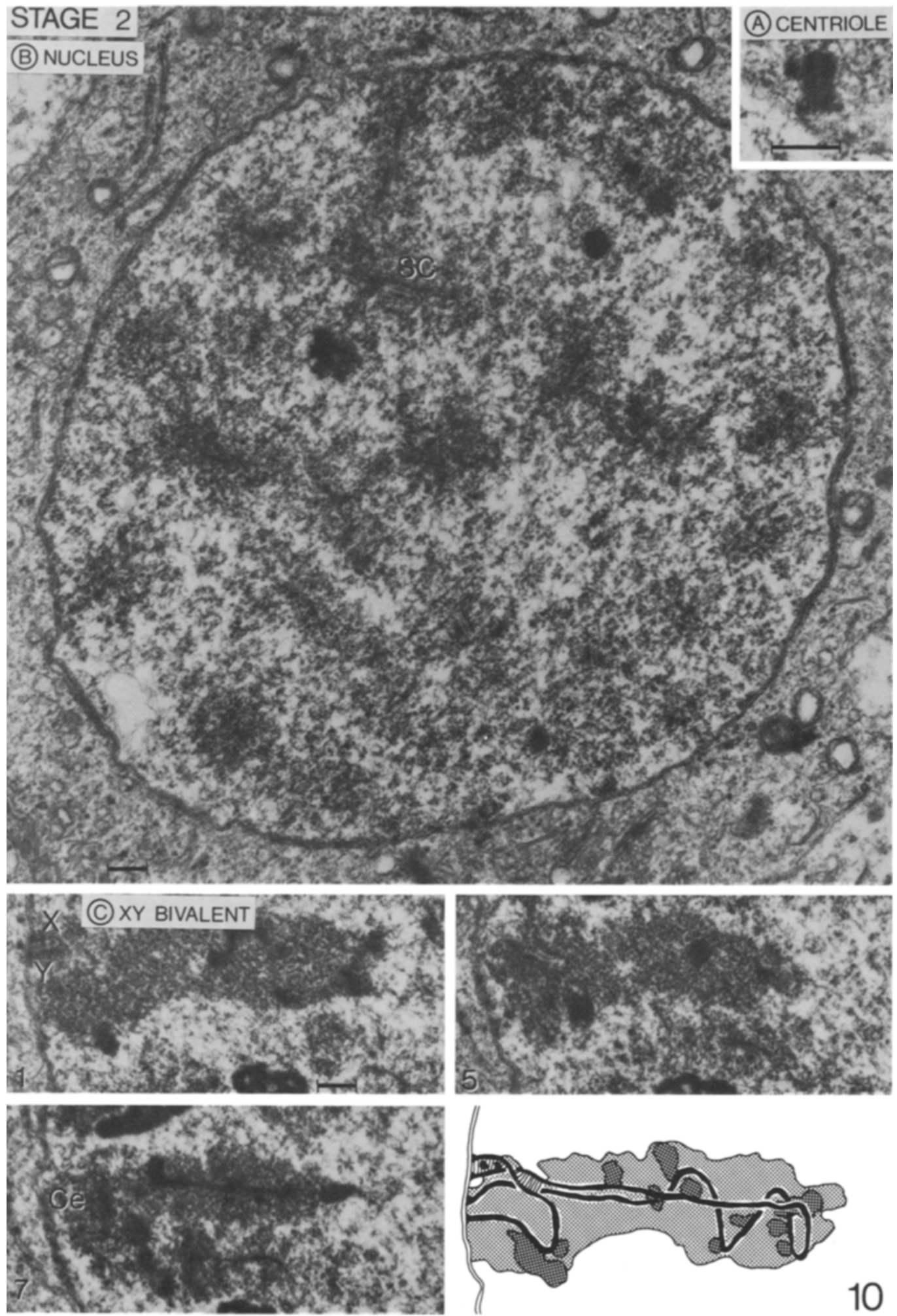

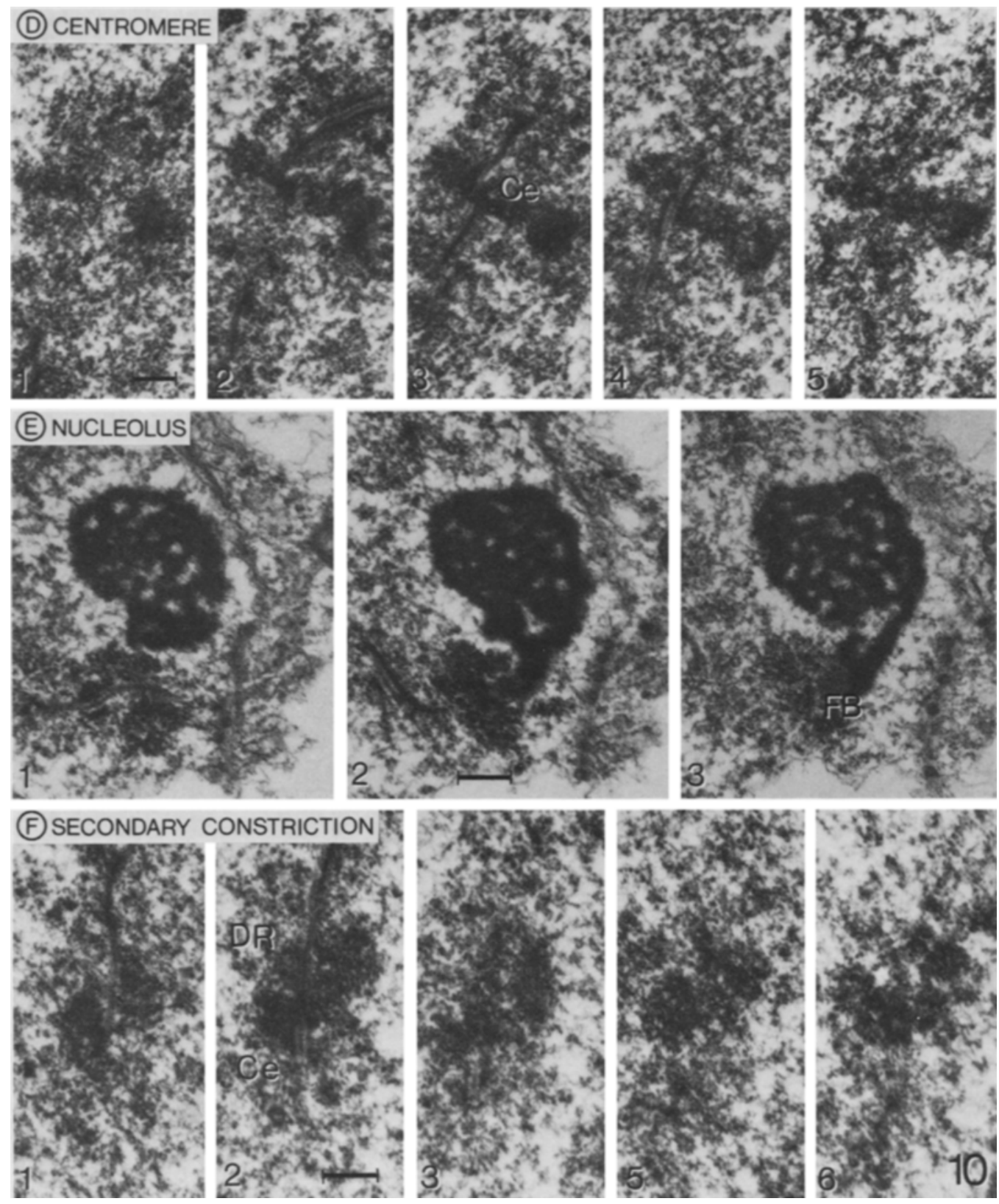

Figure 10. Stage 2 (early pachytene). SC, synaptonemal complex. LC, lateral component. Ce, centromere region. $\mathrm{FB}$, fibrillar body. DR, chromatin of the secondary constriction on bivalent $1 . \mathrm{X}, \mathrm{X}$ chromosome. $\mathrm{Y}, \mathrm{Y}$ chromosome. The numbers are the relative section numbers for the short series of consecutive sections. (Bars $=0.5 \mu \mathrm{m}$ ). 

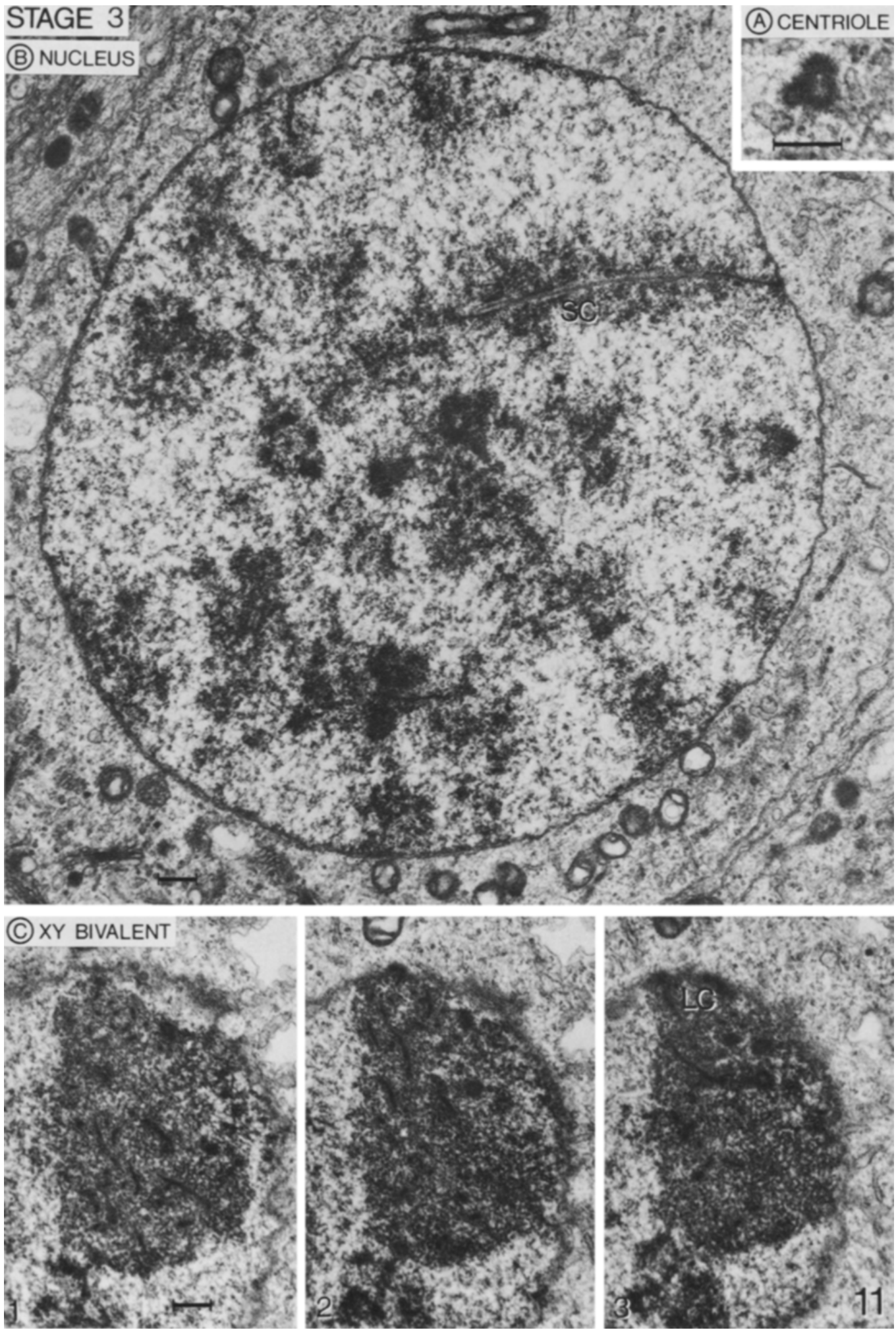

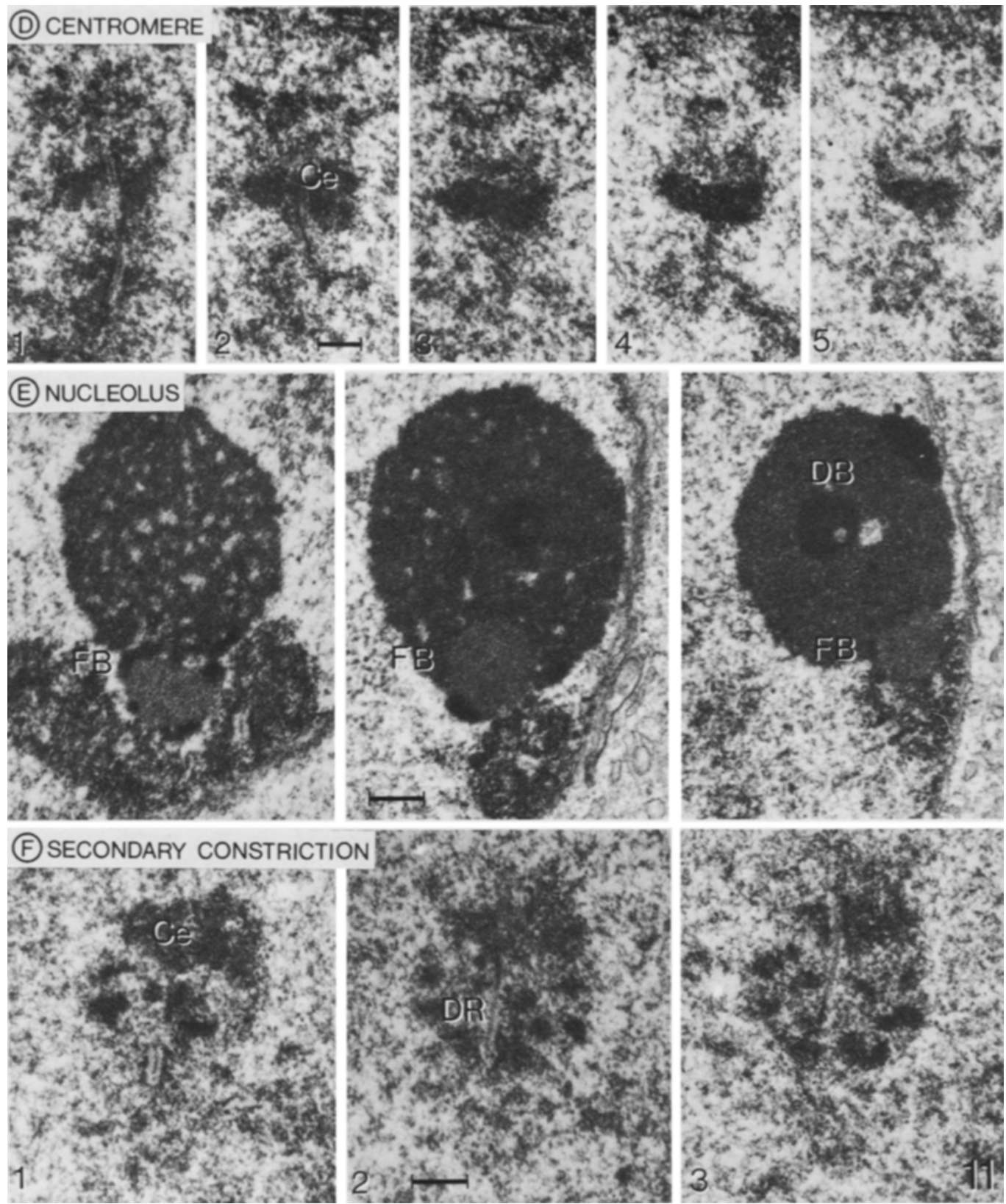

Figure 11. Stage 3 (mid pachytene). SC, synaptonemal complex. LC, lateral component. Ce, centromere region. $\mathrm{DB}$, dark body. FB, fibrillar body. DR, dimorphic chromatin of the secondary constriction on bivalent 9 . The three micrographs of nucleoli represent an early (left), a middle (mid) and a late (right) type. The numbers are the relative section numbers for the short series of consecutive sections. (Bars $=0.5 \mu \mathrm{m}$ ). 

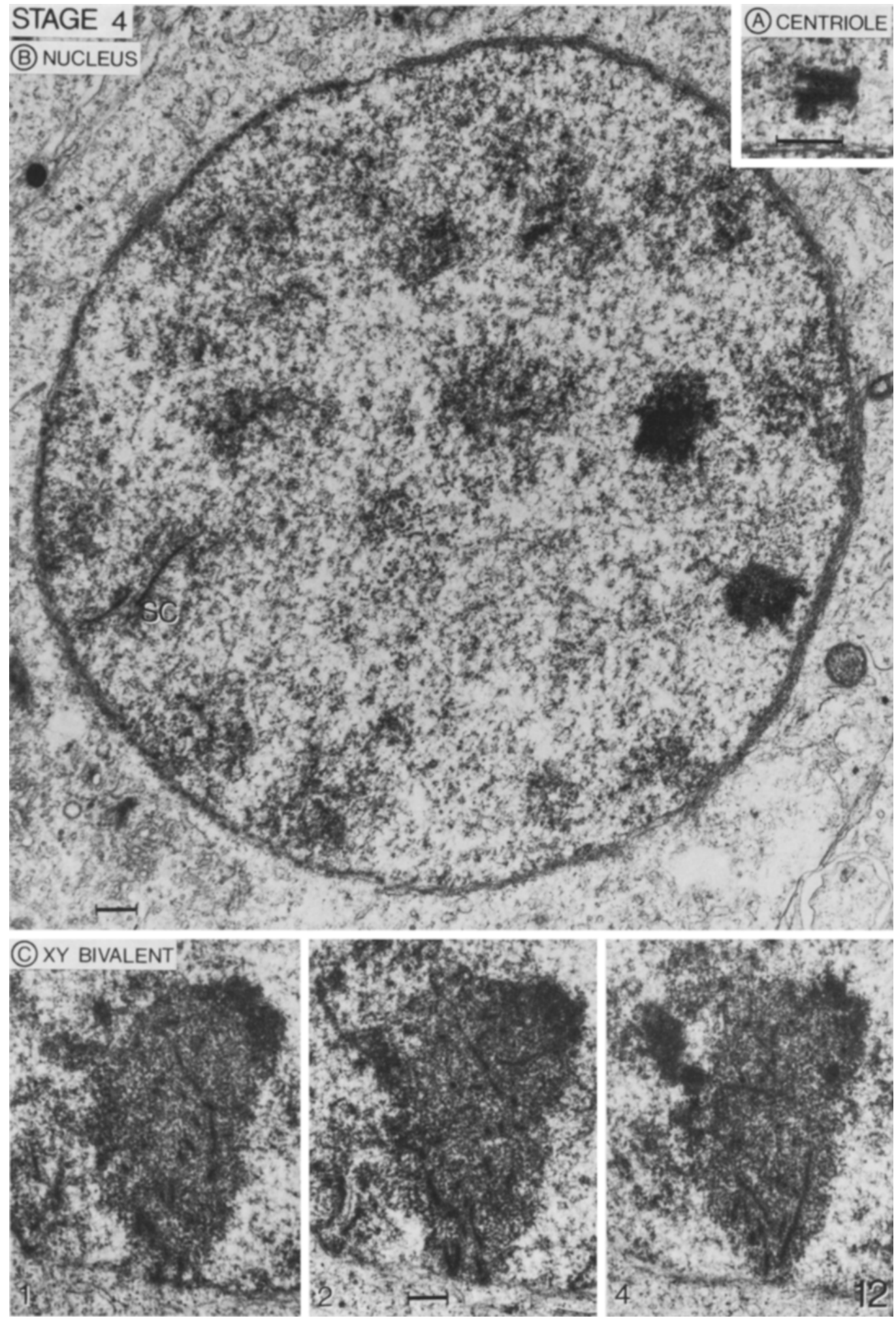

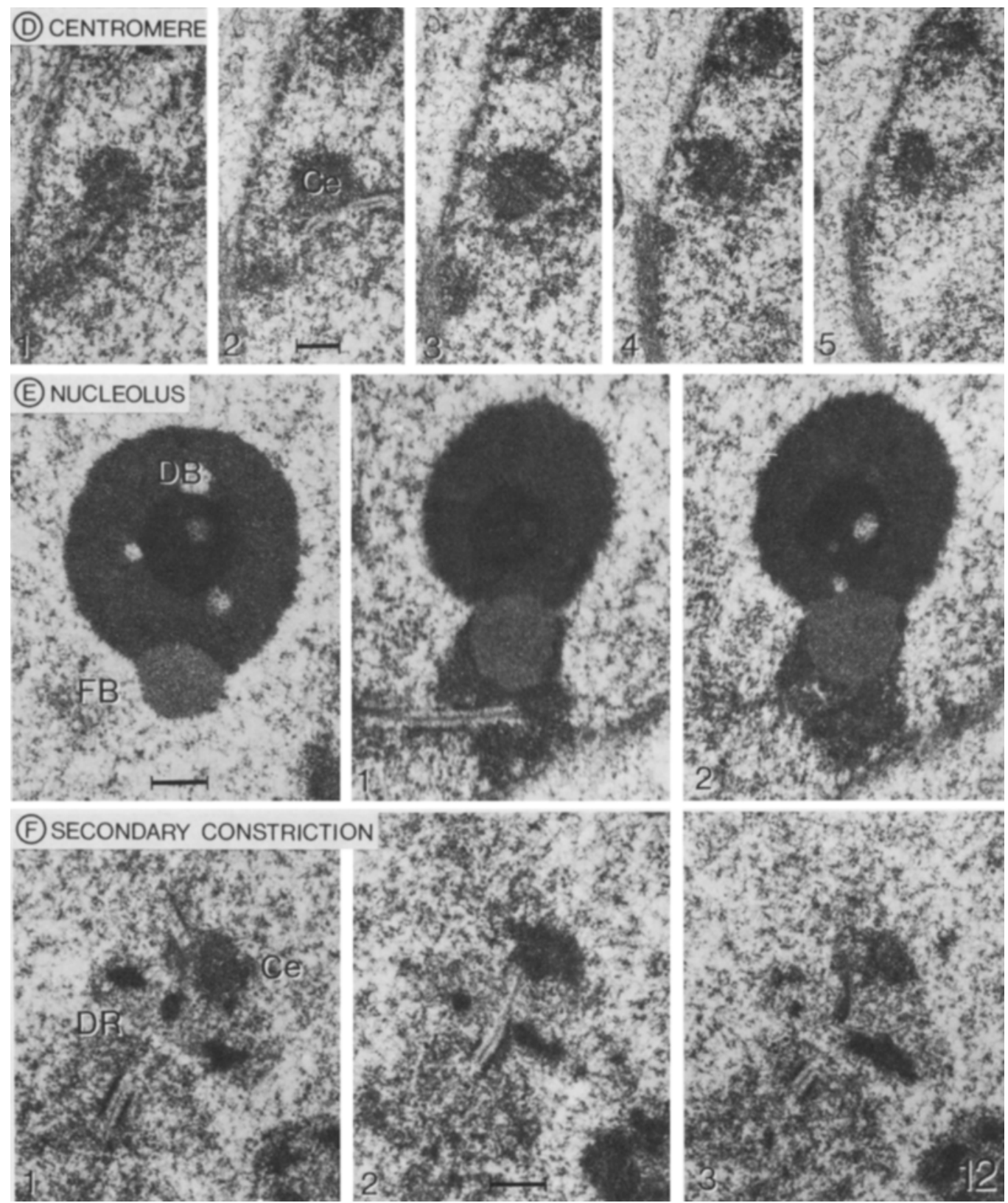

Figure 12. Stage 4 (mid pachytene). SC, synaptonemal complex. Ce, centromere region. DB, dark body. FB, fibrillar body. DR, dimorphic chromatin of the secondary constriction on bivalent 9 . The numbers are the relative section numbers for the short series of consecutive sections. (Bars $=0.5 \mu \mathrm{m}$ ). 

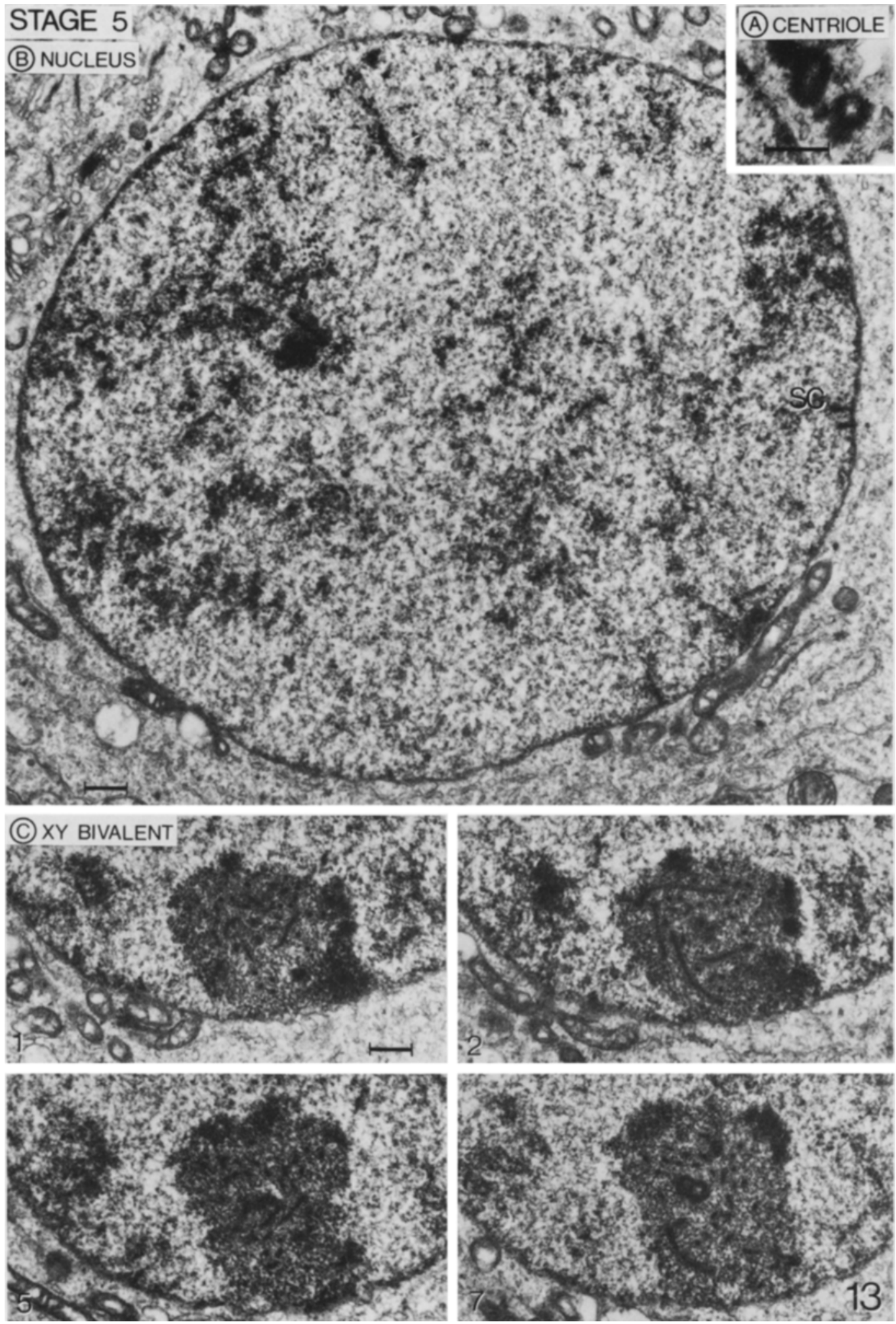

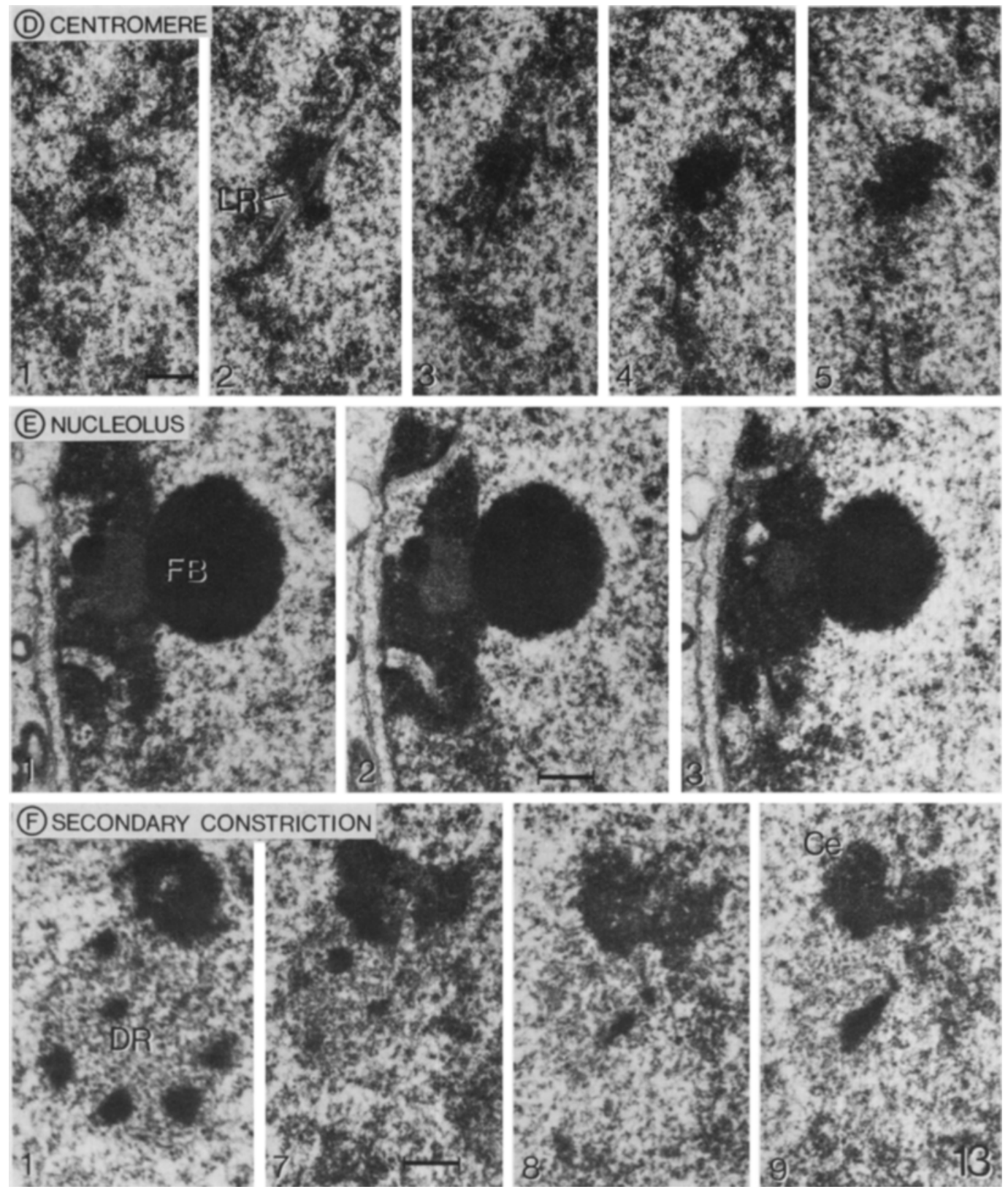

Figure 13. Stage 5 (late pachytene). SC, synaptonemal complex. Ce, centromere region. DB, dark body. FB, fibrillar body. LR, light region of the centromere. DR, dimorphic chromatin of the secondary constriction on bivalent 9. The numbers are the relative section numbers for the short series of consecutive sections. (Bars $=0.5 \mu \mathrm{m}$ ). 

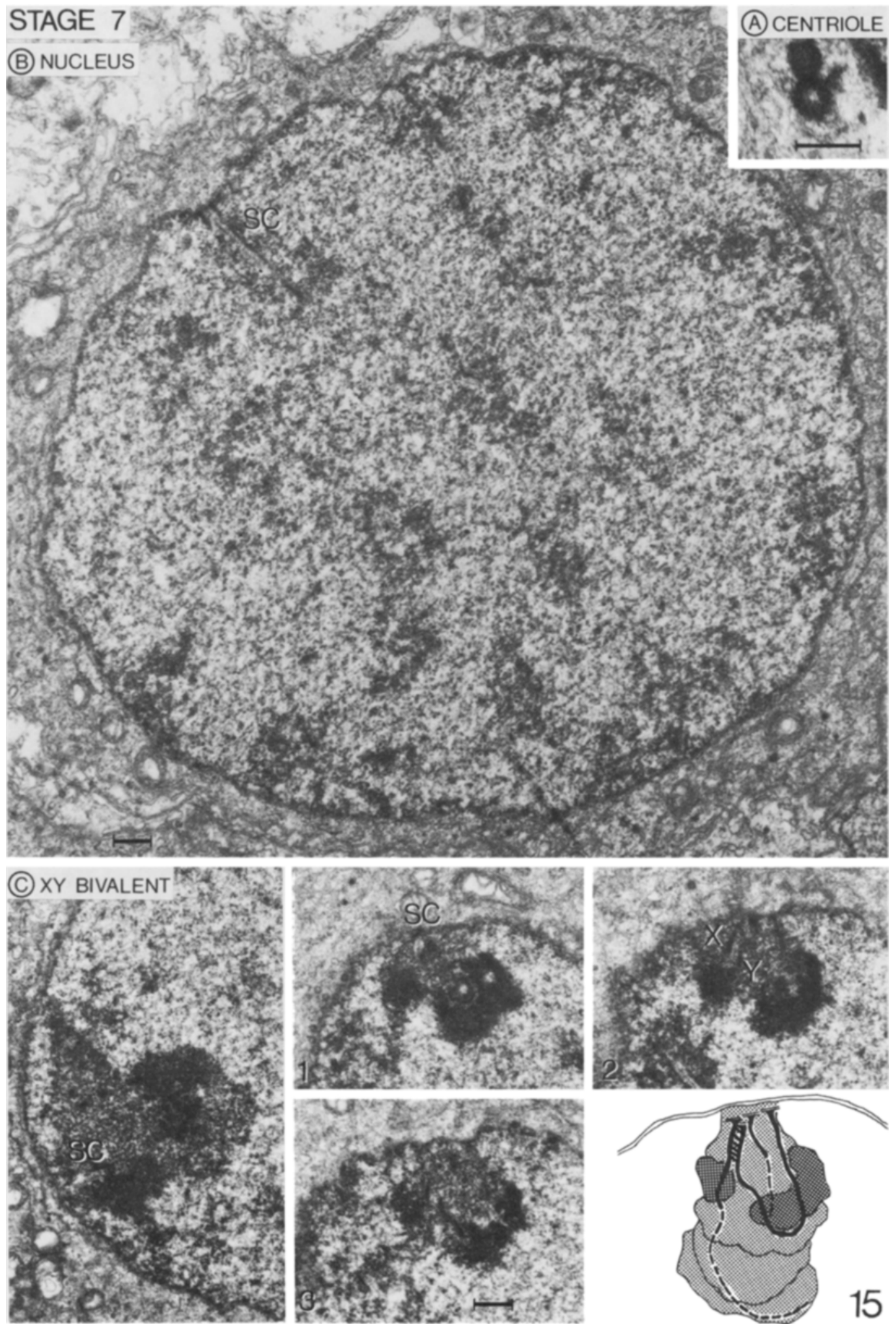

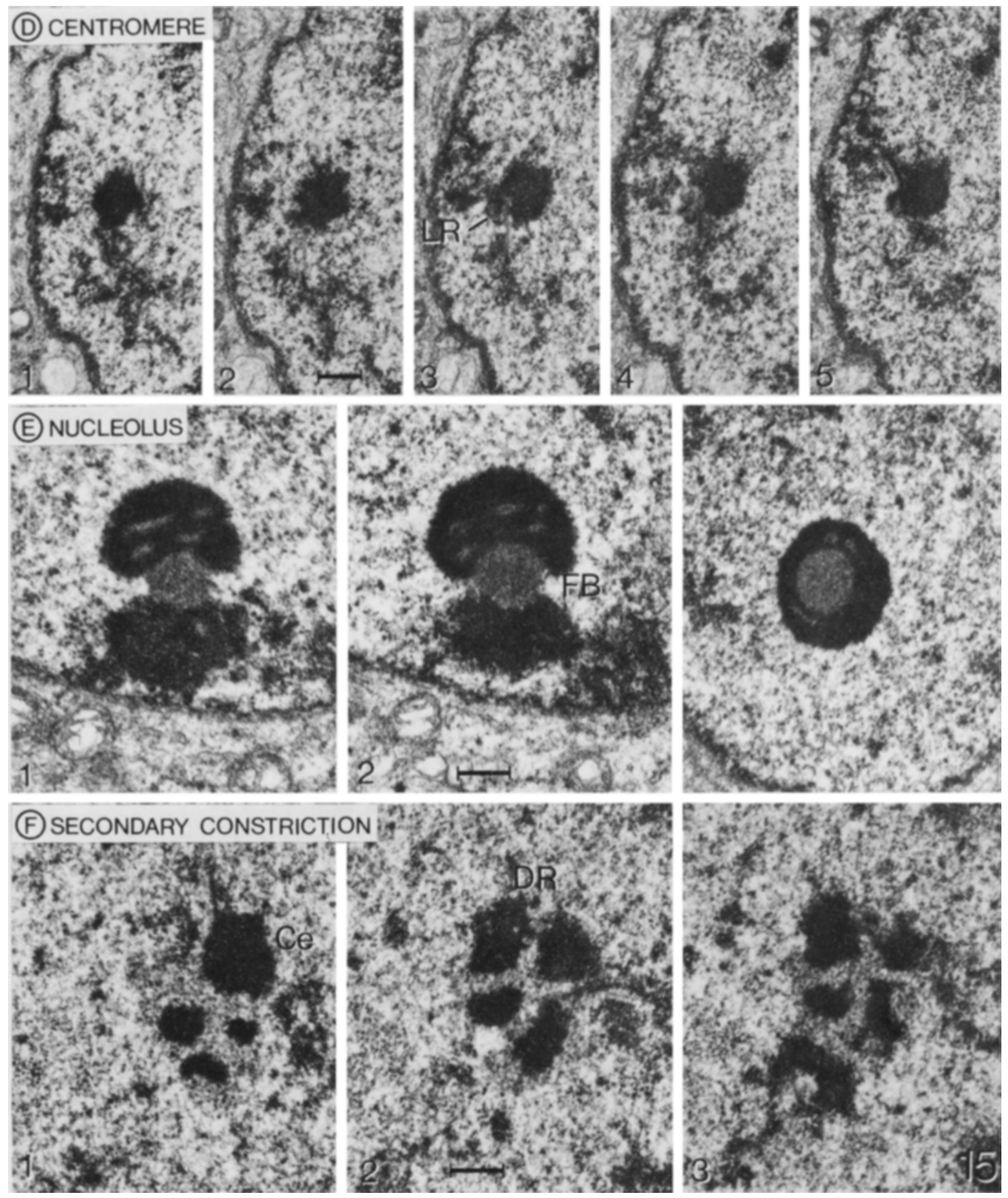

Figure 15. Stage 7 (late pachytene). SC, synaptonemal complex. X, X chromosome. Y, Y chromosome. LR, light region of the centromere. FB, fibrillar body. DR, dimorphic chromatin of the secondary constriction on bivalent 9 . The numbers are the relative section numbers for the short series of consecutive sections. (Bars $=0.5 \mu \mathrm{m}$ ). 

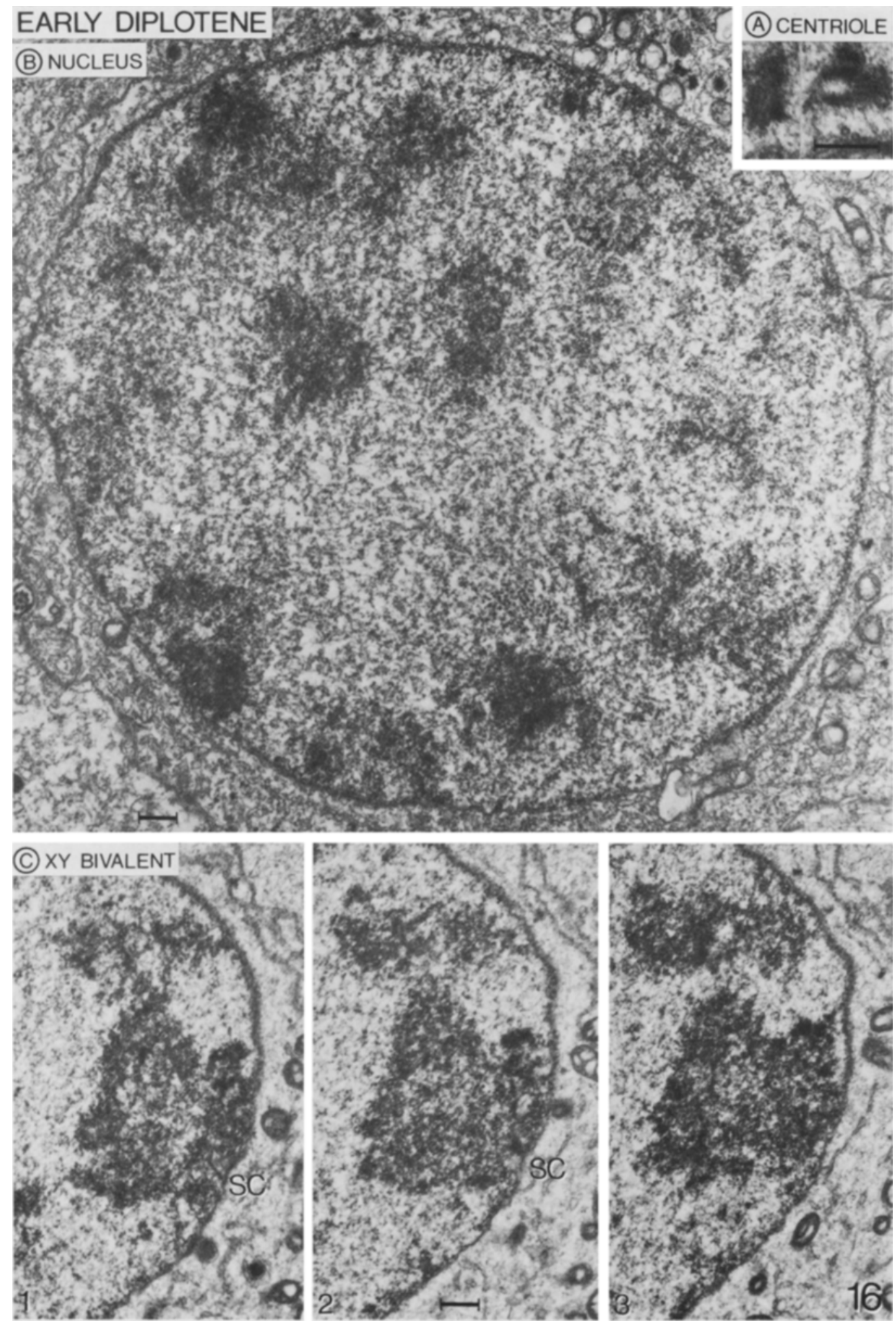

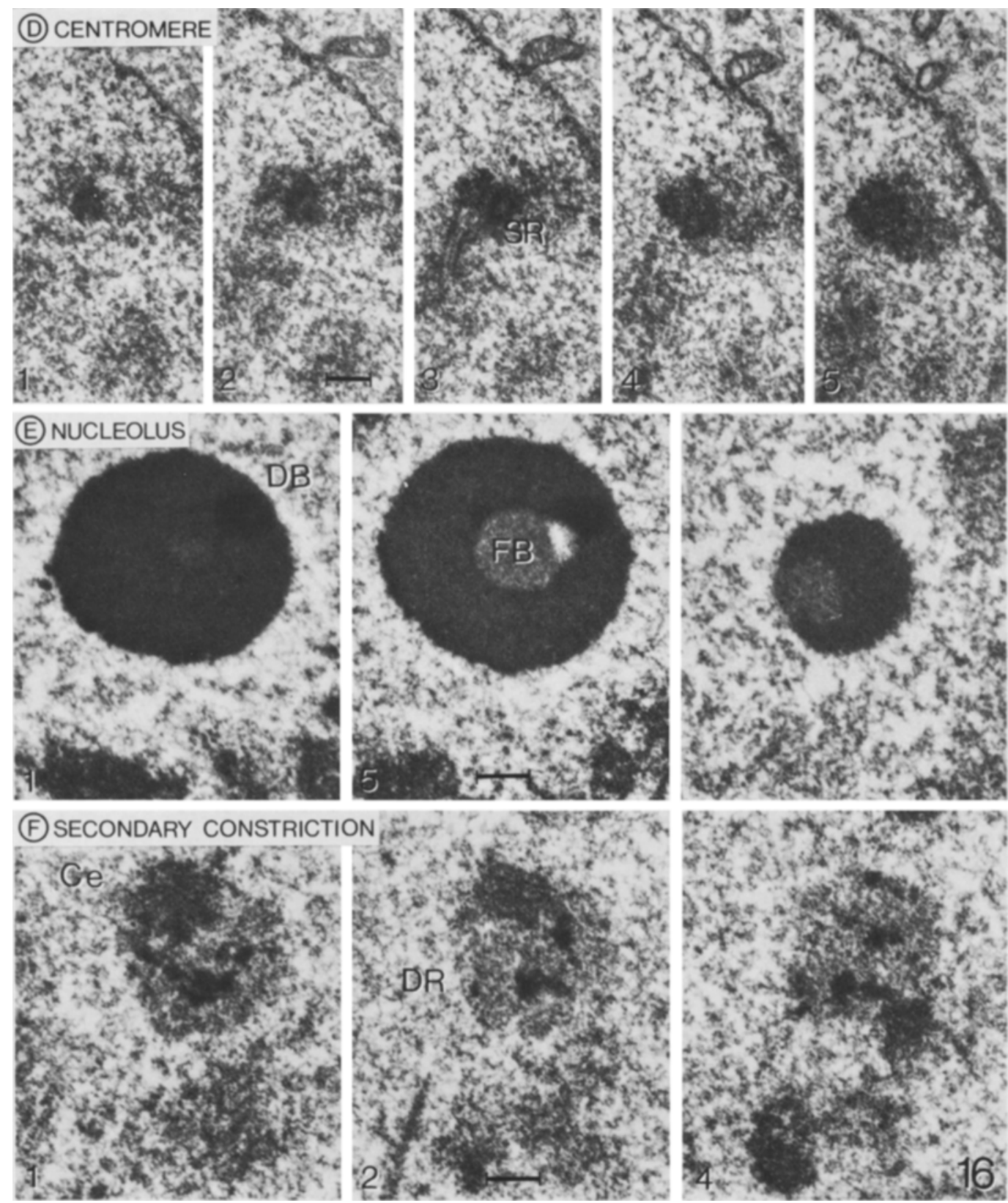

Figure 16. Early diplotene. SC, synaptonemal complex. SR, spherical region of the centromere. DB, dark body. FB, fibrillar body. DR, dimorphic chromatin of the secondary constriction on bivalent 9 . The numbers are the relative section numbers for the short series of consequtive sections. (Bars $=0.5 \mu \mathrm{m}$ ). 